\title{
Seasonal movement and macro-habitat use of largemouth bass (Micropterus salmoides) in an Ohio River navigation pool
}

Jason Gregory Freund

West Virginia University

Follow this and additional works at: https://researchrepository.wvu.edu/etd

\section{Recommended Citation}

Freund, Jason Gregory, "Seasonal movement and macro-habitat use of largemouth bass (Micropterus salmoides) in an Ohio River navigation pool" (2003). Graduate Theses, Dissertations, and Problem Reports. 1725.

https://researchrepository.wvu.edu/etd/1725

This Thesis is protected by copyright and/or related rights. It has been brought to you by the The Research Repository @ WVU with permission from the rights-holder(s). You are free to use this Thesis in any way that is permitted by the copyright and related rights legislation that applies to your use. For other uses you must obtain permission from the rights-holder(s) directly, unless additional rights are indicated by a Creative Commons license in the record and/ or on the work itself. This Thesis has been accepted for inclusion in WVU Graduate Theses, Dissertations, and Problem Reports collection by an authorized administrator of The Research Repository @ WVU. For more information, please contact researchrepository@mail.wvu.edu. 


\title{
Seasonal Movement and Macro-Habitat Use of Largemouth Bass (Micropterus salmoides) in an Ohio River Navigation Pool
}

\author{
Jason Gregory Freund
}

Thesis submitted to

The Davis College of Agriculture, Forestry, and Consumer Sciences

at West Virginia University

in partial fulfillment of the requirement of

Masters of Science

in

Wildlife and Fisheries Resources

Approved by

Kyle J. Hartman, Ph. D., chair

Patricia M. Mazik, Ph. D. Stuart Welsh, Ph. D.

\author{
Division of Forestry \\ Morgantown, West Virginia \\ 2003
}

Keywords: Largemouth bass (Micropterus salmoides), Ohio River, Belleville Pool, radio telemetry, signal attenuation

Copyright 2003 Jason G. Freund 


\section{Abstract \\ Seasonal Movement and Macro-Habitat Use of Largemouth Bass (Micropterus salmoides) in an Ohio River Navigation Pool}

\section{Jason G. Freund}

Largemouth bass provide an important recreational fishery in the Ohio River. Our objectives were to determine critical over-wintering and spawning habitats of largemouth bass in the Belleville Pool of the Ohio River. We surgically implanted radio-transmitters in 39 adult largemouth bass and tracked them over a 23-month period. Our results demonstrate the importance of off-channel habitats in the life history of largemouth bass in large river systems. Sedimentation, resulting in a loss of embayment quality and surface area, is an important problem and thus merits increased attention. Restoration and protection efforts to improve largemouth bass fisheries in large river systems should be concentrated in embayment habitats. In a related experiment, a model that related depth of transmitter to the maximum distance of detection imply that radio telemetry studies may underestimate use of deep-water habitats by fishes. 


\section{Acknowledgments}

The author wishes to his parents for their support. My committee members, Drs. Kyle Hartman, Stuart Welsh, and Patricia Mazik, were instrumental in the completion of this project and should be commended. Scott Morrison of the West Virginia Division of Natural Resources (WVDNR) was of tremendous assistance in the planning and execution of the study. Additionally, this study would have suffered greatly without assistance from Gary Batton, also of the WVDNR. Statistical assistance of Dr. William Thayne greatly improved this manuscript. Field assistance from Gary Batton, Corey and Kyle Hartman, Eric Janney, Scott Morrison, Karen Sacilotto, and Clif Tipton was greatly appreciated. 


\section{CHAPTER 1: INTRODUCTION TO LARGE RIVER ECOLOGY,}

LARGEMOUTH BASS BIOLOGY, AND RADIO TELEMETRY PERTINENT TO THE OHIO RIVER ADULT LARGEMOUTH BASS TELEMETRY PROJECT....1

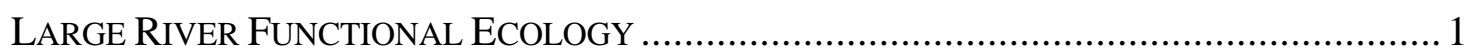

LARGE RIVER MULTIPLE USE AND FISHERIES MANAGEMENT …................................. 3

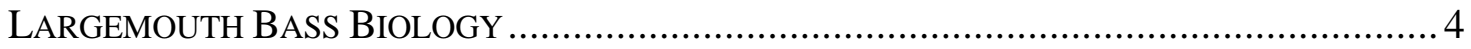

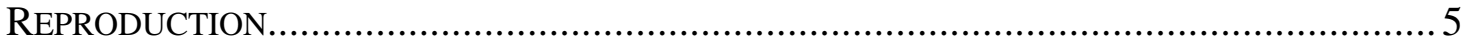

THE OHIO RIVER AND THE BELLEVILLE POOL ……................................................ 7

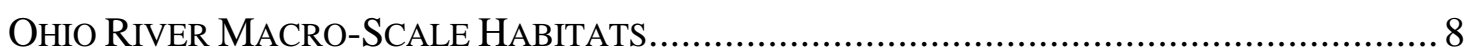

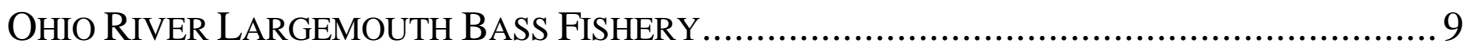

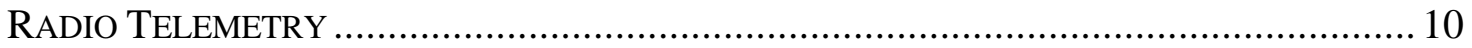

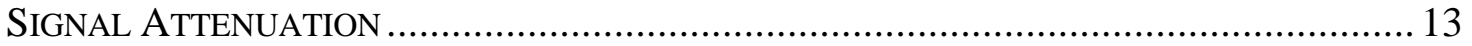

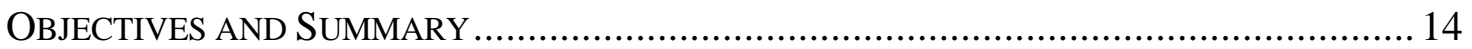

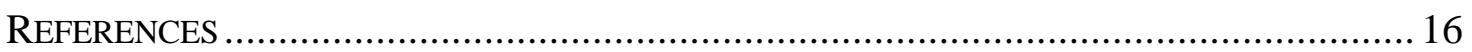

Tables

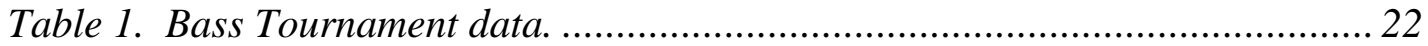

CHAPTER 2: INFLUENCE OF DEPTH ON SIGNAL ATTENUATION OF LOWFREQUENCY RADIO TRANSMITTERS IN AQUATIC SYSTEMS. .....................23

ABSTRACT

Tables

Table 1. Mean distance of maximum signal detection .............................................36

Figures

Figure 1. Distance of maximum signal detection.................................................. 37

Figure 2. Linear relationship between maximum distance of signal detection and

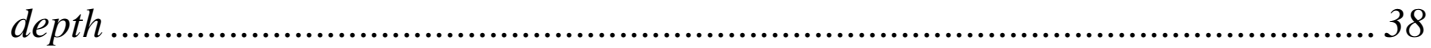

Figure 3. Non-linear relationship between maximum distance of signal detection and depth

CHAPTER 3: SEASONAL MOVEMENT AND MACRO-HABITAT USE OF LARGEMOUTH BASS (MICROPTERUS SALMOIDES) IN AN OHIO RIVER NAVIGATION POOL.

ABSTRACT …

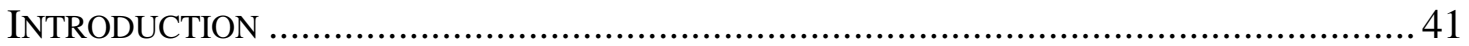

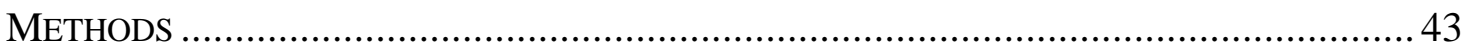

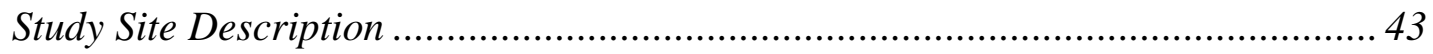

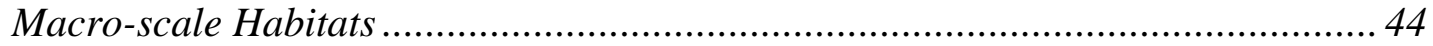

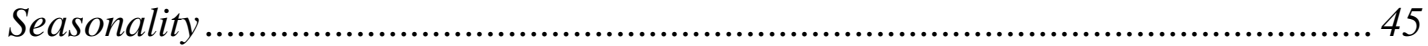

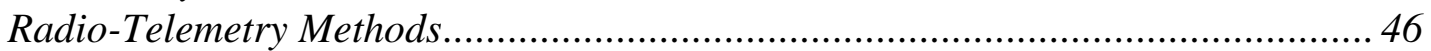




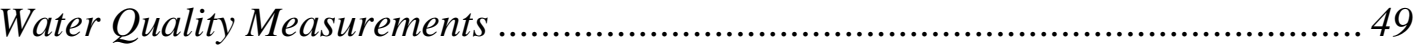

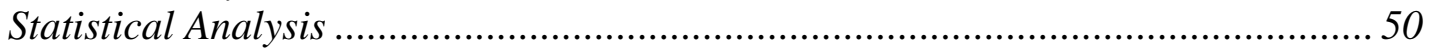

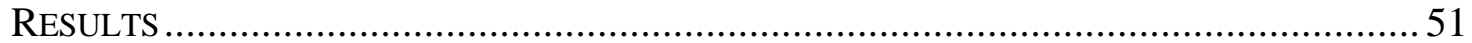

Telemetered Fish .................................................................................... 51

Observed Fish Behavior Patterns .................................................................... 53

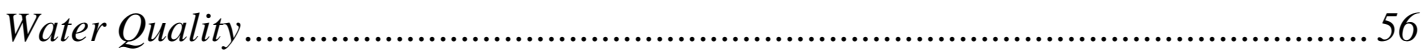

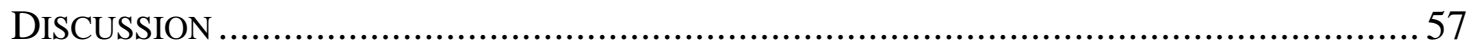

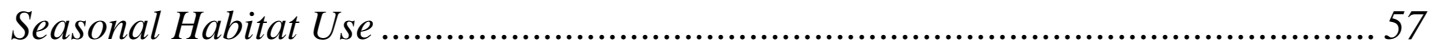

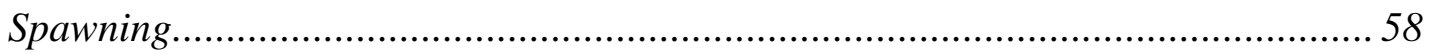

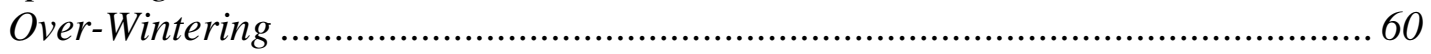

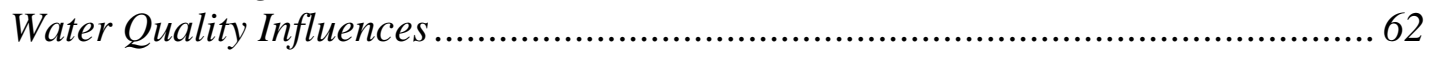

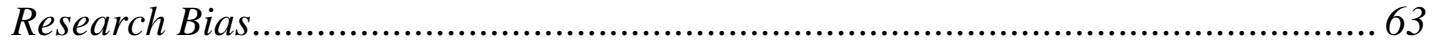

Management Recommendations and Future Research .................................... 65

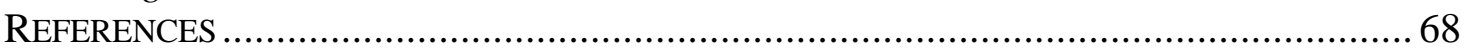

Tables

Table 1. Summary of largemouth bass size distribution .................................... 72

Table 2. Summary of capture date, location, and method .................................. 75

Table 3. Summary of release locations for tournament caught largemouth bass... 78

Table 4. Summary of individual largemouth bass telemetry observations.............. 79

Table 5. Chi-square analysis of overall and seasonal habitat use ....................... 81

Table 6. Effect of capture method on habitat use by largemouth bass.................... 82

\section{Figures}

Figure 1. Position of United States Army Corps of Engineers navigation dams in relation to the state of West Virginia............................................................. 83

Figure 2. Location of major landmarks within the Belleville Pool of the Ohio River

Figure 3. Macro-habitat units in the Belleville Pool of the Ohio River................. 85 Figure 4. Seasonal habitat availability and use by largemouth bass in the Belleville

Pool of the Ohio River................................................................................. 86

Figure 5. Winter and spring habitat use of macro-habitat units in the Belleville

Pool of the Ohio River.............................................................................. 87

Figure 6. Movement of a largemouth bass implanted with a radio transmitter with a

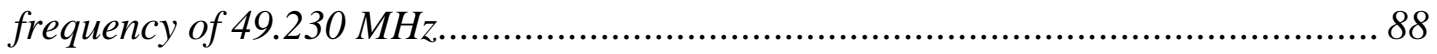

Figure 7. Movement of a largemouth bass implanted with a radio transmitter with a

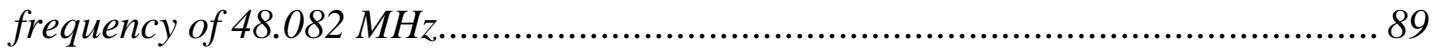

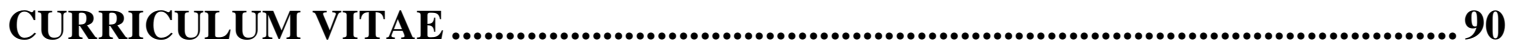




\section{Chapter 1: Introduction to Large River Ecology, Largemouth Bass Biology, and Radio Telemetry pertinent to the Ohio River Adult Largemouth Bass Telemetry Project.}

\section{Large River Functional Ecology}

Our understanding of large river ecosystems is greatly hampered by the lack of historical research on unaltered large rivers ecosystems and the lack of large, unaltered river ecosystems. Consequently, separating natural processes from human-induced processes is exceedingly difficult. Rivers of stream order greater than sixth order are generally classified as large rivers (Sheehan and Rasmussen 1999). Depending upon the latitude, regional precipitation regimes, geology, and a host of other factors large rivers can vary widely in their functional ecology.

Based on the energy equilibrium theory of fluvial geomorphologists (Leopold and Langbein 1962, Leopold et al. 1964), Vannote and five colleagues (1980) proposed the river continuum concept $(\mathrm{RCC})$ to describe the theoretical structure of lotic systems. The RCC proposes that a predictable energy gradient exist from headwater streams to the river mouth within lotic systems.

Downstream energy transfer and the subsequent utilization by downstream organisms is the foundation of the RCC's hierarchical structure. The RCC utilizes the ratio of primary production to community respiration $(\mathrm{P} / \mathrm{R})$ to quantify energy losses or gains within lotic systems. In general, respiration is greater than productivity in headwater reaches due to extensive shading and substantial input of coarse particulate organic matter (CPOM) through leaf fall and large woody debris inputs. Terrestrial inputs become less important as river width increases. Consequently, primary production increases due to the decrease in canopy shading and a subsequent increase in light 
penetration. In addition, fine particulate organic matter (FPOM), the result of processing CPOM by upstream biota, is transferred downstream and is utilized by collectors. In these medium-sized streams (orders 4-6) production, dependent upon rooted vascular plants and algae, is greater than respiration (see Figure 1, Vannote et al. 1980).

Biota of large river ecosystems are assembled to utilize organic materials received from upstream processing inefficiencies. Water depth and elevated turbidity generally limit primary production; consequently respiration is greater than production (Vannote et al. 1980). Inputs from riparian vegetation are insignificant due to the low ratio of riparian zone to river surface area. Most of the organic matter transported from upstream processing inefficiencies is in the form of FPOM. Consequently, collectors, macroinvertebrates that utilize FPOM, dominate benthic communities. However, inputs from the floodplain may outweigh inputs transported from upstream (Junk et al. 1989, Johnson et al. 1995).

Ward and Stanford (1983) proposed the serial discontinuity concept (SDC) to account for interruptions in the longitudinal gradient of river systems attributed to the impoundment of lotic systems. The SDC recognizes that a gradient similar to the RCC gradient exists within individual large river impoundments. The lotic conditions below a dam are typical of upstream conditions while lentic conditions caused by impoundment are typical of downstream conditions within the river system. The SDC explains the abbreviated river continuum within an impoundment. The RCC may still apply to the river as a whole, while the SDC is representative of processes occurring within an impounded river section. 
The flood pulse concept (FPC) accounts for the importance of off-channel and floodplain areas in the functioning of large river ecosystems (Junk et al. 1989). They theorized that organic matter produced and consumed in the floodplain is more important to higher trophic levels than are organic inputs from upstream. Lateral interactions with the floodplain are important in sediment deposition (Wilkin and Hebel 1982, Trimble and Knox 1984), nutrient input (Junk et al. 1989), and in the natural history of many riverine fishes (Kwak 1988, Junk et al. 1989, Raibley et al. 1997b).

Most large river floodplains have been effectively disconnected from the main channel by impoundment and a series of dikes and levees. For instance, Gore and Shields (1995) estimated that the floodplain of the Mississippi River has been reduced by 90\%. Impoundment of the historic floodplain and alteration of flow regimes has also reduced the interaction between the river and its floodplain. In general, the RCC is most applicable to rivers with disconnected floodplains while the FPC is applicable to rivers with floodplains that are not disconnected to the main river.

\section{Large River Multiple Use and Fisheries Management}

Most large river impoundments are designed to meet specific societal needs such as municipal and agricultural water supply, commercial navigation, flood control or hydroelectric power. Primary uses of large rivers take precedence over fishery concerns in large river systems. Secondary recreational activities associated with large rivers, particularly recreational angling, are often underutilized despite the large acreage of water they encompass. In West Virginia, for instance, the Ohio River comprises approximately 50 percent of the available warm water surface acreage in the state. 
Ecological alterations associated with the shift from a lotic to a lentic environment created by the impoundment of a river create far-reaching impacts. Changes in fish assemblages are predicted by changes in physical conditions. Species associated with lotic environments are reduced in number and abundance upon impoundment due to the reduction in flow and increase in depth. Lentic species, once confined to pools within the river, have a much greater amount of potential habitat. This creates a longitudinal gradient of fish community characteristics in rivers downstream from disturbances caused by dams (Bain and Boltz 1989).

Increased deposition of sediment associated with reduced current velocity physically modifies impounded rivers. Upon impoundment, a decrease in turbidity is likely (Baxter 1977, Petts 1984). Shallow main channel border areas and embayments are most affected by sedimentation due to their shallower depth and reduced current velocities. Many Mississippi River backwater habitats are expected to be lost to sedimentation within the next 50 to 100 years (Sheehan and Rasmussen 1999) and onefourth have been filled within the last 35 years (UMRBC 1982). These areas comprise the most important spawning areas for nest-building species such as centrarchids (Miller and Kramer 1971). Sedimentation may limit recruitment for centrarchids and other fish relying on solid substrates for successful spawning limiting populations (Bulkley 1975).

\section{Largemouth Bass Biology}

Largemouth bass, Micropterus salmoides (Lacepede), are an important sport fish species native through much of North America and introduced elsewhere. Their native distribution includes the Mississippi River drainage from northeastern New Mexico to Florida, and north to the Great Lakes drainages of southern Canada. In the Atlantic 
drainage they occur from southern Florida northward to central South Carolina (Lee 1980). In West Virginia, the largemouth bass occurs in all major drainages (Stauffer et al. 1995). Largemouth bass can reach sizes up to $11 \mathrm{~kg}$ (Lee 1980). In West Virginia, the longest specimen on record is $65.1 \mathrm{~cm}$ and the heaviest specimen weighed $4.9 \mathrm{~kg}$ (Stauffer et al. 1995).

\section{Reproduction}

Largemouth bass invest a large amount of energy into spawning and reproduction (Gillooly and Baylis 1999, Mackereth et al. 1999). Consequently, spawning is one of the most stressful and important activities in their life history. Largemouth bass, and centrarchids in general, create and guard a nest, a parental strategy that is energy intensive (Gross 1984). Largemouth bass males construct a nest by digging a shallow depression in the substrate while clearing the nest of small sediment. Males attract a female to their territory where she will deposit eggs that the male will fertilize. Males will defend the nest from egg and fry predators for several weeks following egg deposition (Gross 1984).

Disturbance events during the crucial nest-guarding period may cause recruitment failure of individual nests and of year classes (Hershfeld et al. 1986, Kieffer, et al. 1995, Lukas and Orth 1995, Philipp et al. 1997). Disturbance events can result from environmental variability or anthropogenic causes. It is not readily known how environmental and human-induced disturbances interact or how they may manifest themselves at the population level.

Stochastic environmental events exert themselves on a large scale and lead to the variability of year class strength among years (e.g. Grossman et al. 1982). Flood increase 
current velocities and sediment load often resulting in nest failure. For riverine smallmouth bass Micropterus dolomieu, increased water velocity at nest sites is the most likely reason for nest failure (Lukas and Orth 1995). At the other extreme, severe drought may dewater the nest, causing the fish to abandon the nest (Hershfeld et al. 1986, Nielsen et al. 1986, Nack et al. 1993). Large fluctuations in water elevation or temperature may cause egg or fry death and reduce reproductive success (Hershfeld et al. 1986, Lukas and Orth 1995).

Human caused disturbances may act on individual nests or at the population level (Baylis 1995). Increases in sedimentation rates due to development or land-use practices may vary in their effect on bass reproductive success relative to the magnitude and scale of disturbance. Angling has been shown to increase nest predation and result in lower nest success (Philipp et al. 1997). Male smallmouth bass that were caught and fought to exhaustion took four times longer to return to their nest than those played only briefly (Kieffer 1995). Dependent upon the amount of angling pressure, angling may have population level impacts on largemouth bass. Hayes et al. (1995), in a model simulating the effects of competitive angling, determined that nesting disruption reduced the amount of angling effort that could be sustained. However, most research has been conducted at the level of the individual nest and estimates of the effect of black bass angling at the population level are lacking.

The impoundment of large rivers dramatically altered the ecology of most of North America large river systems. Nielsen et al. (1986), in a review of the biological impacts of navigation, referred to the increase in centrarchid populations in the Mississippi and Ohio Rivers as the only clearly positive impact of navigation 
engineering. Activities associated with commercial navigation may affect year class formation. Fluctuations in impoundment elevation and wakes caused by barge traffic agitate substrate resulting in increased turbidity and the resultant deposition of suspended solids on developing eggs. Changes in impoundment elevation and barge-induced wakes can leave nest dewatered (Hershfeld et al. 1986) causing nest failure.

\section{The Ohio River and the Belleville Pool}

The Ohio River, formed by the confluence of the Monongahela and Allegheny Rivers in Pittsburgh, Pennsylvania, is a 2,102 $\mathrm{km}$ river that has been highly altered for commercial navigation. Twenty United States Army Corps of Engineers (USACE) lock and dam structures maintain a 3.7 m navigation channel. Navigation pools, defined by upstream and downstream dams, are typically 40 to $80 \mathrm{~km}$ in length. This creates a system defined by a series of long, narrow and relatively deep impoundments. The Ohio

River system can no longer be considered riverine (sensu Sheehan and Rasmussen 1989).

The Ohio River has a long history of human-alteration. From 1837 to 1966, 47 back channel dikes and 111 training dikes were built to increase channel depth to improve navigation. Between 1875 and 1900, five low-lift lock and dams created a $2 \mathrm{~m}$ deep navigation channel. Increased activity from 1900 through 1930 resulted in the building of 51 low-lift lock and dams to create a $2.75 \mathrm{~m}$ deep navigation channel. Since 1930, the 51 low-lift structures were replaced by 13 high-lift lock and dam structures creating the present $3.7 \mathrm{~m}$ deep navigation channel (ORSANCO 1994).

The Belleville Pool is created by the Belleville Lock and Dam at river kilometer 328.1 and is bound upstream by the Willow Island Lock and Dam at river kilometer 260.2. The $67.9 \mathrm{~km}$ long pool averages $404.5 \mathrm{~m}$ in width, $7.3 \mathrm{~m}$ deep and encompasses 
2850 ha. As in other areas, a channel of at least $3.7 \mathrm{~m}$ is maintained for commercial navigation by the USACE (ORSANCO 1994). Forty-five tributaries enter within the Belleville Pool, including the Little Kanawha River and the Muskingum River, which are commercially navigable.

The riparian zone is largely developed and industrialized, particularly in proximity to cities. The cities of Marietta, $\mathrm{OH}$, and Parkersburg, WV, located at the confluence of the Muskingum River and Little Kanawha River, respectively, comprise the largest population centers within the Belleville Pool riparian zone.

\section{Ohio River Macro-Scale Habitats}

In studying Belleville Pool largemouth bass, we chose macro-scale habitat units as our most refined spatial scale. This avoided introducing error associated with radio telemetry triangulations and the inability to differentially correct our global positioning system (GPS) coordinates into our conclusions. Our objectives focused on determining the seasonal distribution of largemouth bass within the Ohio River where large spatial scales are most important. Using a relatively large spatial scale assured that triangulation error would not exceed our spatial scale. That is, error associated with triangulation and GPS would never be large enough to incorrectly place a fishes' location in an incorrect habitat unit.

Macrohabitats within the Ohio River were divided into three main components; the main channel, tributaries and embayments.

The main channel includes all of the area that is between the Ohio and West Virginia shorelines. Off-channel borders are areas within the main river located near the shorelines but are shallower than the nine-foot depth maintained for commercial 
navigation. Confluence areas are located where an embayment or tributary connects to the main channel and influences local conditions. Discharge areas are those areas affected by an industrial outfall. Back channels, the channel formed by an island that is outside of the main current flow, are important areas for many river fishes .

Tributaries are important as seasonal fish habitats and in delivering water, nutrients, and sediments from the watershed to the river. We defined tributaries as streams that have an average discharge exceeding 10,000 cfs and are typically more riverine than embayments. Within the Belleville Pool, the Muskingum River, Little Kanawha River, Little Hocking River, and the Hocking River meet the guidelines to be considered tributaries.

In many large rivers, embayments are critical seasonal habitats for many fish species. The flooding of smaller tributary stream floodplains by Ohio River main channel impoundments generally forms embayments. These habitats usually have little current flow under normal conditions and are areas of sediment deposition and may serve as a current or thermal refuge for fish (Carlson 1992, Gent et al. 1995, Raibley et al. 1997a, 1997b)

\section{Ohio River Largemouth Bass Fishery}

The Ohio River Recreation Use Survey (Schell et al. 1996) analyzed angler use of the Ohio River through roving creel surveys in 1992 and 1993. Anglers spent 276,657 hours in the Belleville Pool in 1992. Only the Hannibal pool experienced more angler hours $(298,236)$ than Belleville during survey. Black bass (Micropterus sp.) were the second most sought after group of species with $16.9 \%$ of anglers and 57,019 hours spent 
specifically targeting black bass. Only temperate basses (Morone sp.) were pursued with more angling effort (17.0 percent of anglers and 58,568 angler hours).

Anglers, particularly those associated with tournaments, perceived a decline in the numbers of largemouth bass in the Ohio River during the late 1990's. Recreational and tournament fishing for black bass on the Ohio River are popular activities. Tournament data dating back to 1975 illustrate that the number of tournaments hosted within the Belleville pool has generally increased (Table 1) suggesting a general increase in angling effort during this period. In 1998, due to the perceived decline in the black bass fishery, black bass anglers, particularly those associated with tournaments, urged the West Virginia Division of Natural Resources to study the Ohio River largemouth bass fishery.

\section{Radio Telemetry}

Radio telemetry is a common fisheries technique. In general, a transmitter is affixed to a fish either through surgical implantation, gastro-intestinal implantation, or is externally attached to the fish. Transmitters emit a signal at a predetermined interval and frequency that is received by a radio receiver. The signal may then be triangulated from known locations or the signal strength can be used to determine the transmitter's location.

Advances in technology have greatly changed the application and versatility of radio telemetry since it was first used in the late 1960's (Winter 1996). Early radio telemetry studies were limited to using larger fish for shorter periods of time (Henderson et al. 1966, Warden and Lorio 1975, and Winter 1977). Recent advances in technology have permitted development of smaller, more powerful transmitters that have allowed researchers to study smaller fishes, follow the same fish for longer periods of time, and over greater spatial scales. Additionally, technological advances have enable researchers 
to collect environmental variables such as depth and temperature (Coutant and Carroll 1980) and physiological responses such as heart rate (Demers et al. 1996) with radio transmitters.

Radio telemetry must be modified to match the constraints of the system and the fish of concern (Winter 1996). In general, radio telemetry is appropriate when large amounts of information are required from individuals or information is required over a long period of time. Radio telemetry is particularly well suited for researching movement across various spatial scales, large-scale habitat use, home range determination, temperature and depth selection, and natural mortality. Radio telemetry is also well suited for research of anadromous fishes, highly mobile, and rare fishes. Automated receiver stations can be designed to address specific movement questions. These fixed stations can collect more data than researchers would otherwise be able to collect. Radio telemetry is well suited for use with small populations since a large amount of information may be collected from a single fish.

Radio telemetry has many limitations and is not suitable for all research needs. Due to the cost of equipment and the large amount of labor that is necessary, radio telemetry studies are expensive to conduct. Efforts and costs associated with implanting and tracking fish necessitate that sample sizes are smaller than traditional mark and recapture studies. Although radio telemetry is well suited for researching small populations, sample sizes may be limited due to the inability to capture specimens for transmitter attachment. However, once a fish is fitted with a transmitter, a large amount of data can be collected from a single fish. Habitat complexity and water depth and conductivity may limit the ability to detect radio telemetry signals (Stasko and Pincock 
1977). Additionally, precision of fish locations is limited by global positioning system accuracy and availability of differential corrections for positions.

Large rivers are particularly difficult to sample effectively and have been historically neglected by researchers (Sheehan and Rasmussen 1999). In the past decade, radio telemetry has been used increasingly to address many large river fisheries questions. Biotelemetry is suited for use with large or rare species such as sturgeon (Acipenseridae; Haynes et al. 1978, Wooley and Crateau 1985, Curtis et al. 1997), paddlefish (Polyodon spathula; Teaford 1997), and catfishes (Ictaluridae; Hart and Summerfelt 1975) that are associated with large river ecosystems. Game fishes including striped bass (Morone saxatilis; Dudley et al. 1977, Carmichael et al. 1998), hybrid striped bass (M. chrysops x M. saxatilis; Petering and Johnson 1991, Vallazza 1995), walleye (Stizostedion vitreum; Schlagenhaft and Murphy 1985, Paragamian 1989, Pitlo 1989), sauger (S. canadense; Petering and Johnson 1991, Pegg et al. 1997), largemouth bass (Schlagenhaft and Murphy 1985, Bruno et al. 1990, Carlson 1992, Nack et al. 1993, Gent et al. 1995, Rogers and Bergersen 1995, Raibley 1997a), and other centrarchids (Centrarchidae; Knights et al. 1995) have been studied using radio telemetry on large river ecosystems and impoundments.

While much work has been completed on large river fishes, differences between large river systems may make conclusions derived in one river inapplicable to other systems. The discontinuity forged by human alteration of large river systems may even create situations where different areas within a system are incomparable. For instance, the proportion of river area comprised of backwater areas in the upper Mississippi River valley is twice as extensive as for the Ohio River valley (Nielsen et al. 1986). 
Consequently, habitats used by fishes within the upper Mississippi River may differ from those used by fishes in the Ohio River.

Due to their importance as a game fish, largemouth bass are one of the most extensively studied freshwater fishes. Radio telemetry has been used to study largemouth bass in lakes (Winter 1977, Fish and Savitz 1983, Mesing and Wicker 1986, Bruno et al. 1990), rivers (Carlson 1992, Nack et al. 1993, Gent et al. 1995, Raibley 1997a), estuaries (Richardson-Heft et al. 2000), and impoundments (Jackson and Brown-Peterson 1995, Rogers and Bergersen 1995). Within large rivers, largemouth bass biotelemetry research has been published from the Mississippi River (Pitlo 1986, Sheehan et al.1994, Gent et al. 1995), the Illinois River (Raibley 1997a), and the tidal Hudson River (Carlson 1992, Nack et al. 1993). Despite the relatively large amount of literature from large river systems, many of the conclusions may not be applicable to the Ohio River since great differences exist between large river ecosystems.

\section{Signal Attenuation}

Radio telemetry signal strength is lost or attenuated by the physical environment. Radio signal frequency, water density, conductivity, and depth influence signal attenuation. Additionally, physical habitat may limit the strength of the signal escaping the aquatic environment. Increases in aquatic vegetation, structural complexity and river sinuosity may increase signal attenuation (Stasko and Pincock 1977). Low frequency transmitters (40-80 MHz) are recommended for use in highly conductive waters $(400 \mu \mathrm{S}$ or greater specific conductivity). The manufacturer (Advanced Telemetry Systems) reports that signal detection with a hand-held loop antenna is approximately $1 \mathrm{~km}$. 
Detection with a large four element Yagi-style antenna was approximated at $2 \mathrm{~km}$ (Chris Kochany, Advanced Telemetry Systems, personal communication).

During my research, I witnessed several fish that were undetected during tracking efforts only to be located the next time I tracked. This led to the hypothesis that fish may be using deep water and the signal is attenuated so greatly that the probability of detection is greatly reduced. An experiment was devised to determine the distance at which we could detect a signal at a given depth. From these data, a model was built to describe the relationship between water depth and conductivity and the maximum distance of signal detection. The probability that a signal is detected is directly proportional to the maximum distance at which a signal can be detected.

Others have noted the importance of signal attenuation, but little research has been directed in this area. Otis and Weber (1982) quantified that signal attenuation increased with depth. Their findings, however, examined only moderate depths of 2 and 5 feet. There is a lack of research that quantifies the loss of signal strength despite its importance within aquatic systems to radio telemetry studies. The inability to detect fish in deep, highly conductive, or highly complex habitats can bias conclusions from radio telemetry studies.

\section{Objectives and Summary}

My objective was to quantify seasonal habitat use and movement of largemouth bass within the Ohio River, providing managers with information to help them make sound scientific management decisions regarding largemouth bass. To accomplish the objectives we conducted a radio telemetry study, tracking largemouth bass over a 23 month period. In conjunction with the radio telemetry study, an experiment was 
performed to determine the maximum distance at which a low-frequency radio signal could be detected at different depths. This experiment was conducted in response to several occasions were fish that had previously been detected were not detected during later a radio telemetry search leading to the hypothesis that fish that are using deep water habitats may not be detected during radio telemetry searches. Our results will give fish managers information on largemouth bass habitat use specific to the Ohio River 


\section{References}

Bain, M. B., and J. M. Boltz. 1989. Regulated streamflow and warmwater stream fish: a general hypothesis and research agenda. U. S. Fish and Wildlife Service Biological Report 89(18):1-28.

Baxter, R. M. 1977. Environmental effects of dams and impoundments. Annual Reviews of Ecological Systematics 8:255-283.

Baylis, J. R. 1995. The population-level consequences of individual reproductive competition: observations from a closed population. Pages 217-226 in Noakes, J. L., Editor. Evolution and the aquatic ecosystem: defining unique units in population conservation. American Fisheries Society Symposium 17, Bethesda, Maryland.

Bruno, N. A., R. W. Gregory, H. L. Schramm, Jr. 1990. Nest sites used by radio-tagged largemouth bass in Orange Lake, Florida. North American Journal of Fisheries Management 10:80-84.

Bulkley, R. V. 1975. Chemical and physical effects on the Centrarchid basses. Pages 286-294 in Stroud, R. H. and H. Clepper, editors. Black bass biology and management. Sport Fishing Institute, Washington, D.C.

Carlson, D. M. 1992. Importance of wintering refugia to the largemouth bass fishery in the Hudson River Estuary. Journal of Freshwater Ecology 7(2): 173-180.

Carmichael, J. T., S. L. Haeseker, J. E. Hightower. 1998. Spawning migration of telemetered striped bass in the Roanoke River, North Carolina. Transactions of the American Fisheries Society 127: 286-297.

Coutant, C.C., and D.S. Carroll. 1980. Temperatures occupied by ten ultrasonic-tagged striped bass in freshwater lakes. Transactions of the American Fisheries Society 109:195-202.

Curtis, G. L., J. S. Ramsey, and D. L. Scarnecchia. 1997. Habitat use and movement of shovelnose sturgeon in Pool 13 of the upper Mississippi River during extreme flow conditions. Environmental Biology of Fishes 50:175-182.

Demers, E., R. S. McKinley, A. H. Weatherley, and D. J. McQueen. 1996. Activity patterns of largemouth and smallmouth bass determined with electromyogram biotelemetry. Transactions of the American Fisheries Society 125: 434-439.

Dudley, R. G., A. W. Mullis, and J. W. Terrell. 1977. Movements of adult striped bass (Morone saxatilis) in the Savannah River, Georgia. Transactions of the American Fisheries Society 106:314-322. 
Fish, P. A., and J. Savitz. 1983. Variations in home ranges of largemouth bass, yellow perch, bluegills, and pumpkinseeds in an Illinois lake. Transactions of the American Fisheries Society 112:147-153.

Gent, R., J. Pitlo, Jr., and T. Boland. 1995. Largemouth bass response to habitat and water quality rehabilitation in a backwater of the upper Mississippi River. North American Journal of Fisheries Management 15:784-793.

Gillooly, J. F., and J. R. Baylis. 1999. Reproductive success and the energetic cost of parental care in male smallmouth bass. Journal of Fish Biology 54:573-584.

Gore, J. A., and F. D. Shields. 1995. Can large rivers be restored? Bioscience 45:142152.

Gross, M. R. 1984. Sunfish, salmon, and the evolution of alternative reproductive strategies and tactics in fishes. Pages 55-75 in G. W. Potts, and R. J. Wootton, editors. Fish reproduction: strategies and tactics. Academic Press, Orlando, FL.

Grossman, G. D., P. B. Moyle, and J. O. Whitaker, Jr. 1982. Stochasticity in structural and functional characteristics of an Indiana stream fish assemblage: a test of community theory. The American Naturalist 120:423-454.

Hart, L. G. and R. C. Summerfelt. 1975. Surgical procedures for implanting ultrasonic transmitters into flathead catfish (Pylodictis olivaris). Transactions of the American Fisheries Society 104:56-69.

Hayes, D. B., W. W. Taylor, and H. L. Schramm, Jr. 1995. Predicting the biological impact of competitive fishing. North American Journal of Fisheries Management $15: 457-472$.

Haynes, J. M., R. H. Gray, and J. C. Montgomery. 1978. Seasonal movements of white sturgeon (Acipenser transmontanus) in the Mid-Columbia River. Transactions of the American Fisheries Society 107:275-280.

Henderson, H. F., A. D. Hasler, and G. C. Chipman. 1966. An ultrasonic transmitter for use in studies of movements of fishes. Transactions of the American Fisheries Society 95:350-356.

Hershfeld, D. C., D. J. Orth, and L. A. Nielsen. 1986. Fish Production in the Kanawha River and its relation to barge traffic. Polish Archives of Hydrobiology 33:295-303.

Jackson, D. C., and N. J. Brown-Peterson. 1995. Habitat, accessibility, and watershed variables as they related to largemouth bass and bluegill in Mississippi's National Forest impoundments. Southeastern Association of Fish and Wildlife Agencies 49:26-36. 
Johnson, B. L., W. B. Richardson, and T. J. Naimo. 1995. Past, present and future concepts in river floodplain ecosystems. BioScience 45:134-141.

Junk, W. J., P. B. Bayley, and R. E. Sparks. 1989. The flood pulse concept in riverfloodplain systems. Canadian Special Publications of Fisheries and Aquatic Sciences 106:110-127.

Kieffer, J. D., M. R. Kubacki, F. J. S. Phelan, D. P. Philipp, and B. L. Tufts. 1995. Effects of catch-and-release angling on nesting male smallmouth bass. Transactions of the American Fisheries Society 124:70-76.

Knights, B. C., D. L. Johnson, and M. H. Sandheinrich. 1995. Responses of bluegills and black crappie to dissolved oxygen, temperature, and current in backwater lakes of the Upper Mississippi River during Winter. North American Journal of Fisheries Management 15:390-399.

Kwak, T. J. 1988. Lateral movement and use of floodplain habitat by fishes of the Kankakee River, Illinois. The American Midland Naturalist 120:241-249.

Lee, D. S. 1980. Micropterus salmoides (Lacepede), largemouth bass. 1980. Page 608 in Lee, D. S., Gilbert, C. R., Hocutt, C. H., Jenkins, R E., McAllister, D. E., and J. R. Stauffer Jr. Atlas of North American freshwater fishes. North Carolina Biological Survey.

Leopold, L. B., M. G. Wolman, and J. P. Miller. 1964. Fluvial processes in geomorphology. Freeman, San Francisco.

Leopold, L. B. and W. B. Langbein. 1962. The concept of entropy in landscape evolution. U. S. Geological Survey Professional Paper 500-A.

Lukas, J. A. and D. J. Orth. 1995. Factors affecting nesting success of smallmouth bass in a regulated Virginia stream. Transactions of the American Fisheries Society 124:726-735.

Mackereth, R. W., D. L. G. Noakes, and M. S. Ridgway. 1999. Size-based variation in somatic energy reserves and parental expenditure by male smallmouth bass, Micropterus dolomieu. Environmental Biology of Fishes 56:263-275.

Mesing, C. L. and A. M. Wicker. 1986. Home range, spawning migrations, and homing of radio-tagged Florida largemouth bass in two central Florida lakes. Transactions of the American Fisheries Society 115:286-295. 
Miller, K. D. and R. H. Kramer. 1971. Spawning and early life history of largemouth bass (Micropterus salmoides) in Lake Powell, Pages 78-83 in Hall, G. E., editor. Reservoir fisheries and limnology. American Fisheries Society Special Publication No. 8, Bethesda, Maryland.

Nack, S. B., D. Bunnell, D. M. Green, and J. L. Forney. 1993. Spawning and nursery habitats of largemouth bass in the tidal Hudson River. Transactions of the American Fisheries Society 122:208-216.

Nielsen, L. A., R. J. Sheehan, and D. J. Orth. 1986. Impacts of navigation on riverine fish production in the United States. Polish Archives of Hydrobiology 33:277294.

Otis, K. J. and J. J. Weber. 1982. Movement of carp in the Lake Winnebago system determined by radio telemetry. Wisconsin Department of Natural Resources Technical Bulletin 134. 16pp.

ORSANCO (Ohio River Valley Water Sanitation Commission). 1994. Ohio River Water Quality Fact Book. Ohio River Valley Water Sanitation Commission, Cincinnati, $\mathrm{OH}$.

Paragamian, V. L. 1989. Seasonal habitat use by walleye in a warmwater river system, as determined by radio telemetery. North American Journal of Fisheries Management 9:392-401.

Pegg, M. A., P. W. Bettoli, and J. B. Layzer. 1997. Movement of sauger in the Lower Tennessee River determined by radio telemetry, and implications for management. North American Journal of Fisheries Management 17:763-768.

Petts, G. E. 1984. Impounded rivers: perspectives for ecological management. John Wiley and Sons, London, England. 326 pp.

Petering, R. W., and D. L. Johnson. 1991. Seasonal behavior, movements, and habitat preferences of hybrid striped bass and sauger in the Ohio River. Ohio Department of Natural Resources, Division of Wildlife. Evaluation of Fish Management Techniques, Federal Aid in Fish Restoration Project F-57-R-13. Performance Report

Philipp, D. P., C. A. Toline, M. F. Kubacki, D. B. F. Philipp, and F. S. Phelan. 1997. The impact of catch-and-release angling on the reproductive success of smallmouth bass and largemouth bass. North American Journal of Fisheries Management 17:557-567.

Pitlo J., Jr. 1986. Mississippi River Investigations. Iowa Conservation Commission, Project No. F-109-R-1. 
Pitlo, J., Jr. 1989. Walleye spawning habitat in Pool 13 of the upper Mississippi River. North American Journal of Fisheries Management 9:303-308.

Raibley, P. T., K. S. Irons, T. M. O'Hara, K. D. Blodgett, and R. E. Sparks. 1997a. Winter habitat used by largemouth bass in the Illinois River, a large riverfloodplain ecosystem. North American Journal of Fisheries Management 17:401412.

Raibley, P.T., T. M. O'Hara, K. S. Irons, K. D. Blodgett, and R. E. Sparks. 1997b. Largemouth bass size distributions under varying annual hydrological regimes in the Illinois River. Transactions of the American Fisheries Society 126:850-856.

Richardson-Heft, C. A., A. A. Heft, D. Fewlass, and S. B. Brandt. 2000. Movement of largemouth bass in northern Chesapeake Bay: relevance to sportfishing tournaments. North American Journal of Fisheries Management 20:493-501.

Rogers, K. B. and E. P. Bergersen. 1995. Effects of a fall drawdown on movement of adult northern pike and largemouth bass. North American Journal of Fisheries Management 15:596-600.

Schell, S. A., D. J. Bright, J. A. Marshall, and M. A. Greenlee. 1996. Ohio River Recreational Use Survey. Federal Aid in Sport Fish Restoration, F-69-P.

Schlagenhaft, T. W., and B. R. Murphy. 1985. Habitat use and overlap between adult largemouth bass and walleye in a West Texas reservoir. North American Journal of Fisheries Management 5:465-470.

Sheehan, R. J., and five coauthors. 1994. Winter habitat requirements and overwintering of riverine fishes. Fisheries Research Laboratory, Southern Illinois University, Carbondale, IL. Final Performance Report F-79-R-6.

Sheehan, R. J. and J. L. Rasmussen. 1999. Large rivers. Pages 529-559 in W. A. Hubert and C. C. Kohler, editors. Inland fisheries management in North America, 2nd edition. American Fisheries Society, Bethesda, Maryland.

Stasko, A. B., and D. G. Pincock. 1977. Review of underwater biotelemetry, with emphasis on ultrasonic techniques. Journal of the Fisheries Research Board of Canada 34:1261-1285.

Stauffer, J. R., Jr., J. M. Boltz, and L. R. White. 1995. The fishes of West Virginia. Academy of Natural Science of Philadelphia. Philadelphia, PA. 389 pp.

Teaford, T. T. 1997. The application of GIS to a paddlefish radio telemetry study. Masters thesis. Saint Mary's University of Minnesota. 
Trimble, S. W., and J. C. Knox. 1984. Comment on 'Erosion, redeposition, and delivery of sediment to Midwestern streams' by D. C. Wilkin and S. J. Hebel. Water Resources Research 20:1317-1318.

UMRBC (Upper Mississippi River Basin Commission). 1982. Comprehensive master plan for the management of the upper Mississippi River system. Minneapolis, MN, Upper Mississippi River Basin Commission.

Vallazza, J. M. 1995. Seasonal movement and habitat use of hybrid striped bass in the Ohio River. Masters thesis, Ohio State University, Columbus, OH.

Vannote, R. L., G. W. Minshall, K. W. Cummins, J. R. Sedell, and C. E. Cushing. 1980. The river continuum concept. Canadian Journal of Fisheries and Aquatic Sciences 37:130-137.

Ward, J. V. and J. A. Stanford. 1983. The serial discontinuity concept of lotic ecosystems. Pages 29-42 in T. D. Fontaine and S. M. Bartell, editors. Dynamics of lotic ecosystems. Ann Arbor Science Publications, Ann Arbor, MI.

Warden, R. L. and W. J. Lorio. 1975. Movements of largemouth bass (Micropterus salmoides) in impounded waters as determined by underwater telemetry. Transactions of the American Fisheries Society 104:696-702.

Wilkin, D. C. and S. J. Hebel. 1982. Erosion, redeposition, and delivery of sediment to midwestern streams. Water Resources Research 18:1278-1282.

Winter, J. D. 1977. Summer home range movements and habitat use by four largemouth bass in Mary Lake, Minnesota. Transactions of the American Fisheries Society 106:323-330.

Winter, J. D. 1996. Advances in underwater biotelemetry. P. 555-590. In Murphy, B. R. and D. W. Willis, editors. Fisheries techniques: second edition. American Fisheries Society, Bethesda, MD.

Wooley, C. M. and E. J. Crateau. 1985. Movement, microhabitat, exploitation and management of Gulf of Mexico Sturgeon, Apalachicola River, Florida. North American Journal of Fisheries Management 5:590-605. 
Table 1. Bass Tournament data. Summary of tournament data from the Belleville Pool of the Ohio River, 1975-1999.

\begin{tabular}{rrrr} 
Year & $\begin{array}{c}\text { Number of } \\
\text { Tournaments }\end{array}$ & $\begin{array}{c}\text { Number of } \\
\text { Black Bass } \\
\text { per Hour }\end{array}$ & $\begin{array}{c}\text { Total Number of } \\
\text { Tournament Hours } \\
\text { Fished }\end{array}$ \\
\hline 1975 & 16 & 0.09 & 6,639 \\
1976 & 16 & 0.07 & 2,929 \\
1977 & 17 & 0.08 & 5,878 \\
1978 & 21 & 0.21 & 4,208 \\
1979 & 14 & 0.04 & 6,646 \\
1980 & 12 & 0.08 & 2,094 \\
1981 & 13 & 0.08 & 2,494 \\
1982 & 13 & 0.08 & 2,349 \\
1983 & 17 & 0.14 & 2,972 \\
1984 & 26 & 0.14 & 6,765 \\
1985 & 24 & 0.10 & 3,284 \\
1986 & 19 & 0.09 & 8,224 \\
1987 & 18 & 0.12 & 3,418 \\
1988 & 9 & 0.19 & 2,600 \\
1989 & 13 & 0.27 & 4,116 \\
1990 & 18 & 0.07 & 7,186 \\
1991 & 19 & 0.10 & 6,440 \\
1992 & 28 & 0.19 & 4,862 \\
1993 & 22 & 0.09 & 4,896 \\
1994 & 30 & 0.14 & 11,986 \\
1995 & 30 & 0.08 & 8,724 \\
1996 & 22 & 0.09 & 7,950 \\
1997 & 32 & 0.04 & 5,842 \\
1998 & 18 & 0.08 & 5,812 \\
1999 & 17 & 0.09 & 7,977 \\
\hline Average & $\mathbf{1 9 . 4}$ & $\mathbf{0 . 1 1}$ & $\mathbf{5 , 4 5 2}$
\end{tabular}




\title{
Chapter 2: Influence of depth on signal attenuation of low-frequency radio transmitters in aquatic systems.
}

\begin{abstract}
Radio telemetry is commonly utilized in large, deep bodies of water to assess fish movement and habitat use. Signal attenuation is related to a host of factors, but most importantly to the depth of the transmitter in the water column and water conductivity. While conducting a biotelemetry study on largemouth bass within the Ohio River, several fish not detected during prior search periods were detected in later searches.

Consequently, we hypothesized that telemetered fish using deep water may not be detected. Therefore, we conducted an experiment to measure the influence of depth on the maximum distance at which a transmitter could be detected. An exponential decay model $\left(\right.$ Distance $\left.=0.9890 * \mathrm{e}^{(0.2005 * \text { depth })}\right)$ was shown to best explain these data. Linearization of the decay model resulted in a coefficient of regression of 0.8307 compared to the linear model $\left(\right.$ Distance $=0.8367-0.08116^{*}$ depth $)$ with a regression coefficient of 0.7755 . Our results imply that radio telemetry studies may underestimate use of deep-water habitats by fishes.
\end{abstract}




\section{Introduction}

Radio telemetry is commonly used to assess fish movement (Curtis et al. 1997, Pegg et al. 1997, Baade and Fredich 1998) and habitat use (Pitlo 1986, Gent et al. 1995, Johnson and Jennings 1998,) within large aquatic systems. Radio telemetry is especially practical with rare fish or when capture or recapture probabilities are low (Haynes et al. 1978, Rinne 1982, Wooley and Crateau 1985, Curtis et al. 1997, Baade and Fredich 1998).

Large river systems are difficult to sample effectively with standard gear (Sheehan and Rasmussen 1999). Due to the difficulty associated with sampling larger rivers, radio telemetry is an effective alternative to mark-recapture and habitat-use studies using conventional sampling or collection gears. Radio telemetry allows researchers to obtain many recapture locations from a single tagged fish, providing a cost-effective sampling method in many large aquatic systems.

Attenuation, the loss radio signal strength, in aquatic systems is a neglected factor in the analysis of radio telemetry data. The strength of the returned signal is affected by many physical and chemical factors. Although previous research has addressed problems associated with radio telemetry signal detection in large aquatic systems, attenuation of signal strength has not been well quantified. Stasko and Pincock (1977) described the relationship between depth and conductivity and signal attenuation and noted the need for research in this field. Their results suggest that radio telemetry signals are attenuated with depth. Otis and Weber (1982) conducted an experiment placing transmitters at depths of two and five feet below the water's surface. They reported average distance of detection to be 0.25 and 0.19 miles, respectively. The experiment conducted again in 
September resulted in a 52\% decrease in the range of the two-foot deep transmitters. However, they did not report differences in conductivity, water temperature or habitat complexity which may have significantly affected their results. Winter (1996) states that the relationship between depth of the transmitter and the range is "almost exponential", but fail to quantify the relationship. Lucas and Batley (1996), for instance, noted the difficulties in detecting telemetry signal in large systems, but have not quantified their signal loss. Winter (1996) noted that radio telemetry is only suitable in water with conductivities above $400-600 \mu \mathrm{S}$ if the animal is located close to the surface.

Signal strength is positively correlated to the probability of detecting a transmitter. Transmitters for aquatic use are generally divided into low frequency, from $40 \mathrm{MHz}$ to $60 \mathrm{MHz}$, and high frequency, greater than $100 \mathrm{MHz}$. Low frequency is recommended when water conductivity exceeds $400 \mu \mathrm{S}$ (Winter 1996) since signal attenuation is greater with high frequency transmitters. Additionally, water temperature and conductivity, structural complexity, aquatic vegetation, and depth of the transmitter determine the distance at which a radio telemetry signal can be detected (Winter 1976, Stasko and Pincock 1977, Winter et al. 1978).

The reduced ability to detect telemetry signals in aquatic systems can greatly influence the conclusions of radio telemetry studies. Differences in detection probabilities between habitats may bias study results. If fish using deep-water habitats are less likely to be detected, results may inaccurately conclude that fish are not utilizing deep-water habitats.

While conducting a biotelemetry study on largemouth bass within the Ohio River, several fish not detected during prior search periods were detected in later searches. 
Movement outside of the search area was unlikely as it would have required fish moving past lock and dam structures or into areas of embayments or tributaries that are not navigable. This lead to the hypothesis that transmitters may not have been detected despite being within the search area. The most likely explanation for this phenomenon may be that fish (transmitters) were too deep to be detected during our surveys.

The objectives of our experiment were to quantify the maximum distance of signal detection at varying levels of depth. The experiment was designed to provide evidence that fish using deep-water habitats are more likely to be undetected during our radio telemetry field surveys. Secondarily, our results will allow researchers to estimate the probability of detection over a range of depths. Additionally, this experiment can serve as the base for spatial modeling of transmitter detection probability.

\section{Methods}

Experiments were conducted within the main channel of the lower portion of the Belleville Pool of the Ohio River. In the Belleville Pool, river depth averages $7.3 \mathrm{~m}$ deep and $404.5 \mathrm{~m}$ wide (ORSANCO 1994). Near the Belleville Dam, river depth and width are greater than the average pool depth and width. The experiment was conducted within a straight section of river to reduce variability due to habitat complexity. The Ohio River, like many other water bodies, develops large seasonal fluctuations in water temperature and conductivity. Weekly and bi-weekly data collection over a twenty-three month period by the author showed that main channel conductivity varied from $146.3 \mu \mathrm{S}$ to 886 $\mu \mathrm{S}$ with 35.9 percent of all main river observations exceeding $500 \mu \mathrm{S}$. Temperature during this same time period ranged from $1.4 \mathrm{C}$ to $31.3 \mathrm{C}$ within the main river and averaged $14.6 \mathrm{C}$. 
The experiment was a block design utilizing repeated measures where two blocks of four transmitters tested the maximum distance of detection at four different depths, which represented the depths available to largemouth bass in our study. Eight lowfrequency transmitters ranging from $48.211 \mathrm{To} 48.745 \mathrm{MHz}$ were randomly assigned to 2 different blocks. Then, each block of four transmitters was randomly assigned to each depth so that each block was assigned to all depths. Within each replicate of depth, the maximum distance of signal detection was recorded twice in each direction while the boat was traveling in a northerly and southerly direction. For each depth replicate, four distance measures were recorded for each depth for each transmitter. Over the two blocks, the maximum distance of detection was measured 16 times for each transmitter.

A block of four transmitters was randomly placed within a plastic cylinder and antennae were extended out of the cylinder through a number of holes drilled in the cylinder. An anchor was dropped to the bottom and firmly attached. From the anchor rope, a buoy was attached at the water surface. The cylinder containing the block of transmitters was attached to the anchor rope at pre-marked depths of 1, 3, 6, and $9 \mathrm{~m}$. The location of the transmitters was recorded using a Garmin 12XL global position system (GPS) receiver.

A 4.9 m jon-boat equipped with an ATS Model 2000 scanning type lowfrequency receiver and a $3.0 \mathrm{~m}$ by $3.7 \mathrm{~m}$ four-element Yagi antenna were used to detect radio signals. The antenna was positioned so the peak of the antennae would be facing the transmitters. The boat motored away from the transmitters at a speed of eight to ten knots. The GPS coordinates were recorded at the location where the signal could no longer be detected. For consistency, the same researcher determined the location where 
the signal could no longer be detected audibly in all measures. This design was utilized to simulate our weekly radio telemetry searches.

The maximum distance of signal detection was measured as the distance from the source of the signal to the location where the signal was no longer audible. The change in latitude and longitude were converted from latitude and longitude coordinates received from the GPS unit into UTM coordinates, which are measured in meters. The maximum distance of detection was determined as the square root of the sum of the change in latitude and longitude. This distance was the hypotenuse of the right triangle and corresponded with the maximum distance between the boat and the transmitter.

The experimental procedure was repeated twice during a five-day period. The initial trial began on 6 February 2000 had to be continued on 7 February 2000 due to darkness. A second trial was completed on 10 February 2000. During the trials, water temperature remained at $2.2 \mathrm{C}$ and water conductivity ranged from $397.9 \mu \mathrm{S}$ to $423.0 \mu \mathrm{S}$ with an average conductance of $408.6 \mu \mathrm{S}\left(o^{=} 12.94\right)$. Trials were run at low water temperatures when signal attenuation was expected to be the greatest.

The experimental design was analyzed using a repeated measures ANOVA with the two groups of four transmitters acting as blocks within the experiment. The interaction of date and depth was used as the error term as it was the best estimate of the variance. The alpha level was set at 0.05 for all statistical tests. Upon a significant ANOVA result, a post-hoc Tukey's studentized range test was used to compare differences between means. Tukey's test was selected since it is the most conservative of the multiple comparison tests (Dowdy and Weardon 1991). 
Regression analysis was used to explain the relationship between depth and the maximum distance of signal detection. All regressions were completed using SAS-STAT linear and non-linear procedures. Non-linear regressions were linearized to compare the coefficients of regression between the lines.

\section{Results}

The maximum distance at which a low-frequency radio telemetry signal could be detected decreased as the depth of the transmitter within the water column increased (Figure 1). The maximum distance a radio signal could be detected varied with depth (Prob. $>\mathrm{F}<0.0001$ ). To determine the cause for the difference, we analyzed the type III sums of squares (random effects) from the ANOVA. Date did not significantly influence the maximum distance of detection. However, depth (Prob. $>\mathrm{F}<0.0001$ ), the interaction between date and depth (Prob. $>\mathrm{F}<0.0001$ ), and transmitters (Prob. $>\mathrm{F}<0.0001$ ) all significantly affected the distance of maximum detection.

Upon detecting a significant effect of transmitter depth on the distance of maximum detection, we used a post-hoc Tukey's studentized range test to determine the order and grouping of the mean distance of maximum detection. The results of our posthoc comparisons failed to detect any means grouping together (Table 1).

Simple linear regression revealed a significant linear relationship between the depth of the transmitter and the maximum distance of detection (ANOVA, $\mathrm{P}>\mathrm{F}=$ $<0.0001, y=0.8367-0.08116 *$ depth, $r^{2}=0.7755$, Figure $\left.2 a\right)$. However, residuals of the linear model suggest that the model fails to accurately explain the relationship between the depth of the transmitter and the maximum distance of detection (Figure 2b). 
Based upon visual analysis of the linear residual plot and the rejection of the linear model, an exponential decay function (Distance $=0.9890^{*} \mathrm{e}^{\wedge}\left(-0.2005^{*}\right.$ depth$)$ was fit to these data. Graphical analysis of non-linear residuals indicated an exponential decay function more thoroughly explained these data (Figure 3a, 3b). Linearization of the non-linear model resulted in a correlation coefficient of 0.8307 compared to the linear correlation coefficient of 0.7755 supporting our use of the exponential model.

\section{Discussion}

Our results support previous research by Otis and Weber (1982) and literature reviews (Stasko and Pincock 1977, Winter 1996) by providing evidence that radio signal detection is significantly attenuated with depth. Our exponential decay model provides a more quantitative description of the effect of depth on radio telemetry signal attenuation than previous studies have provided. Winter (1996) stated that transmitter range decreases almost exponentially with depth. Stasko and Pincock (1977) derived curves to explain the relationship between signal attenuation and conductivity, but do not account for depth. Otis and Weber (1982) recorded average effective ranges at two depths. However, they were unable to infer the nature of the relationship between effective range and depth. In addition, they used depths of 2 and $5 \mathrm{ft}$, which are much shallower than conditions found in most radio telemetry studies.

Signal loss increased exponentially with depth resulting in a decrease in the probability of signal detection as the depth of the transmitter increases. The quantification of signal loss with increasing depth has important implications, particularly for aquatic radio telemetry studies conducted in large, highly conductive waters. The differential probability of signal detection at differing depths may bias conclusions of 
radio telemetry studies. Radio telemetry studies may often underestimate the proportion of fish using deep-water habitats. Consequently, conclusions of many radio telemetry studies may be biased toward fish inhabiting shallow water habitats.

The detection of a highly attenuated signal when using smaller antennae is even more unlikely. A pilot study conducted prior to the experiment reported here utilized a hand-held loop antenna. This study illustrated that signals from transmitters at depths of nine meters were often undetectable even with the boat positioned directly on top of the signal source. Additionally, the maximum distance of signal detection was greatly reduced at all depths. During our field surveys, the hand-held loop antenna is used to obtain more precise triangulations. The loop antenna's inability to receive a strong signal at moderate depths may increase error associated with the estimation of fish location. Consequently, the accuracy of a fish's estimated position may be reduced as depth increases.

Many confounding factors were not included in our simple model that may substantially alter signal attenuation our experiment. Our experimental design focused on the best-case scenario where the antenna peak was directed at the transmitter, habitat complexity was consistent and the choice of study area minimized habitat complexity. Additionally, transmitters used were of the same size, age, and manufacturer to minimize differences between transmitters. Battery size and output influence the strength of the radio signal produced. Smaller and older batteries produce a less intense signal. Consequently, signal attenuation reduces the probability of signal detection compared to a stronger signal. The probability of detecting a signal would also be affected by the travel speed of the boat and the receiver's scan time for each individual transmitter 
frequency. Additionally, the shape of the water body affects how much water can be effectively searched with each boat pass. Our experiment was conducted over a relatively short period of time (10 days) where water temperature and conductivity did not vary greatly. Colder water temperature increases water density leading to an increase in signal attenuation. The strength of the battery output and transmitter output may be reduced as water temperature decreases. Experiments were conducted in cold water as our study designed to examine signal attenuation when it was most likely to impart a significant bias. Signal attenuation increases as water conductivity increases (Stasko and Pincock 1977). Additionally, the depth from which a radio signal originates may interact with several of these above-mentioned factors.

The probability of detection of a signal based upon the transmitters location could be spatially modeled with additional information about the causes and magnitude of signal attenuation. However, due to the complexity and the ever-changing conditions that determine signal attenuation, this may be more an exercise in modeling than a feasible management tool.

Our simple decay model relating the depth of the transmitter to the maximum distance at which that transmitter can be detected under ideal conditions has important implication in our study as well as previous telemetry studies in large, deep water bodies. Our results support our hypothesis that radio tagged fish using deep water habitats are more likely to be undetected by our radio telemetry surveys. The exponential nature of the relationship indicates that when fish are using deep water habitats, researchers must be much closer to the signal source than when fish are in shallower habitats (Table 1). Use of deep-water habitats and the subsequent lack of signal detection may account for 
the several occasions where a fish would not be found during one week's search but was detected during the next search.

The reduction in the probability of signal detection may have added unknown biases into previous research. Largemouth bass are typically associated with shallow water habitat; however, they may use deep water habitats when shallow water habitats are limited. For example, Mesing and Wicker (1986) identified that 8 of 22 largemouth bass were located in open water at least $25 \%$ of the time and considered this to be an underestimate due to their inability to locate transmitter signals at water depths of greater than $3 \mathrm{~m}$. Underestimating largemouth bass use of deep water habitats may result in managers ignoring potentially important deep water habitats in their management plans. 


\section{References}

Baade, U. and F. Fredrich. 1998. Movement and pattern of activity of the roach in the River Spree, Germany. Journal of Fish Biology 52:1165-1174.

Curtis, G.L., J. S. Ramsey, and D. L. Scarnecchia. 1997. Habitat use and movement of shovelnose sturgeon in Pool 13 of the upper Mississippi River during extreme low flow conditions. Environmental Biology of Fishes 50:175-182.

Dowdy, S., and S. Weardon. 1991. Statistics for research, second edition. Wiley Series in Probability and Mathematical Statistics, John Wiley and Sons. 629 pp.

Gent, R., J. Pitlo Jr., and T. Boland. 1995. Largemouth bass response to habitat and water quality rehabilitation in a backwater of the upper Mississippi River. North American Journal of Fisheries Management 15:784-793.

Haynes, J.M., R. H. Gray, and J. C. Montgomery. 1978. Seasonal movements of white sturgeon (Acipenser transmontanus) in the Mid-Columbia River. Transactions of the American Fisheries Society 107:275-280.

Johnson, B.L. and C. A Jennings. 1998. Habitat associations of small fishes around islands in the upper Mississippi River. North American Journal of Fisheries Management 18:327-336.

Lucas, M.C. and E. Batley. 1996. Seasonal movements and behavior of adult barbel Barbus barbus, a riverine cyprinid fish: implications for river management. Journal of Applied Ecology 33:1345-1358.

Mesing, C. L., and A. M. Wicker. 1986. Home range, spawning migrations, and homing of radio-tagged Florida largemouth bass in two central Florida lakes. Transactions of the American Fisheries Society 115:286-295.

ORSANCO, 1994. Ohio River Water Quality Fact Book, Cincinnati, OH.

Pegg, M.A., P. W. Bettoli, and J. B. Layzer. 1997. Movement of saugers in the lower Tennessee River determined by radio telemetry, and their implications for management. North American Journal of Fisheries Management 17:763-768.

Pitlo, J., Jr. 1986. Mississippi River investigations. Project no. F-109-R-1. Iowa Conservation Commission.

Raibley, P.T., K. S. Irons, T. M. O'Hara, K. D. Blodgett, and R. E. Sparks. 1997. Winter habitats used by largemouth bass in the Illinois River, a large river-floodplain ecosystem. North American Journal of Fisheries Management 17:401-412.

Rinne, J.N. 1982. Movement, home range, and growth of a rare southwestern trout in improved and unimproved habitats. North American Journal of Fisheries Management 2:150-157. 
Sheehan, R.J. and J. L. Rasmussen. 1999. Large Rivers. In: Kohler, C.C. and W. A. Hubert (eds), Inland Fisheries Management in North America, American Fisheries Society, Bethesda, MD.

Stasko, A.B. and D. G. Pincock. 1977. Review of underwater biotelemetry, with emphasis on ultrasonic techniques. Journal of the Fisheries Research Board of Canada 34:1261-1285.

Warden, R.L. and W. J. Lorio, 1975. Movements of largemouth bass (Micropterus salmoides) in impounded waters as determined by underwater telemetry. Transactions of the American Fisheries Society 104:696-702.

Winter, J. 1996. Advances in underwater biotelemetry. In: Murphy, B.R. and D. W. Willis (eds), Fisheries Techniques, American Fisheries Society, Bethesda, Maryland, pp. 555-590.

Winter, J. D. 1976. Movements and behavior of largemouth bass and steelhead determined by radio telemetry. Dissertation, University of Minnesota, Minneapolis, MN.

Winter, J.D., V. B. Kuechle, D. B. Siniff, and J. R. Tester. 1978. Equipment and methods for radio tracking freshwater fish. University of Minnesota Agricultural Extension Service Miscellaneous Report 152.

Wooley, C.M. and E. J. Crateau. 1985. Movement, microhabitat, exploitation and management of Gulf of Mexico Sturgeon, Apalachicola River, Florida. North American Journal of Fisheries Management 5:590-605. 
Table 1. Mean distance (DIST $(\mathrm{km})$ ) of maximum signal detection at 1, 3, 6, and $9 \mathrm{~m}$ transmitter depth, corresponding variance, standard error (STD_ERR), and upper and lower 95 percent confidence intervals. A post-hoc Tukey's studentized range test determined mean distance of maximum detection was dissimilar between all depth levels tested $(a ́=0.05)$.

\section{\begin{tabular}{llllll}
\hline DEPTH & FREQ & DIST $(\mathrm{km})$ VARIANCE & STD_ERR & Lower 95\% CI & Upper 95\% CI
\end{tabular}}

\begin{tabular}{ccccccc}
\hline 1 & 64 & 0.79514 & 0.032106 & 0.022398 & 0.75124 & 0.83904 \\
3 & 64 & 0.57478 & 0.021169 & 0.018187 & 0.53914 & 0.61043 \\
6 & 64 & 0.28102 & 0.006510 & 0.010086 & 0.26126 & 0.30079 \\
9 & 64 & 0.15382 & 0.002377 & 0.006094 & 0.14188 & 0.16577 \\
\hline
\end{tabular}


Figure 1. Physical representation of the distance of maximum detection of transmitters at $1,3,6$, and $9 \mathrm{~m}$.

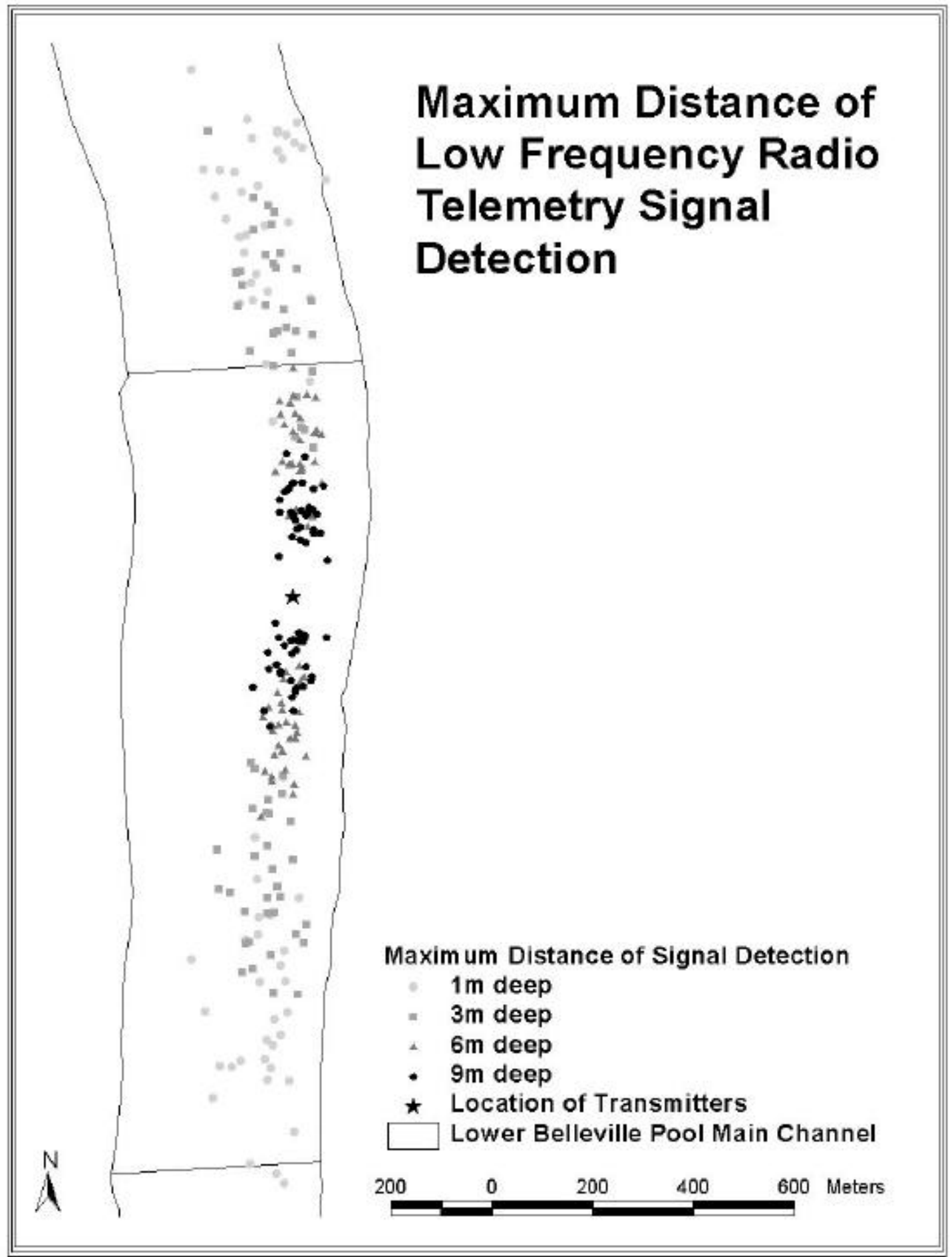


Figure 2. Maximum distance of audible signal detection as a linear function of transmitter depth. $\left(\mathrm{R}^{2}=0.7755, \operatorname{Pr}(>\mathrm{F})=0.0001\right)$

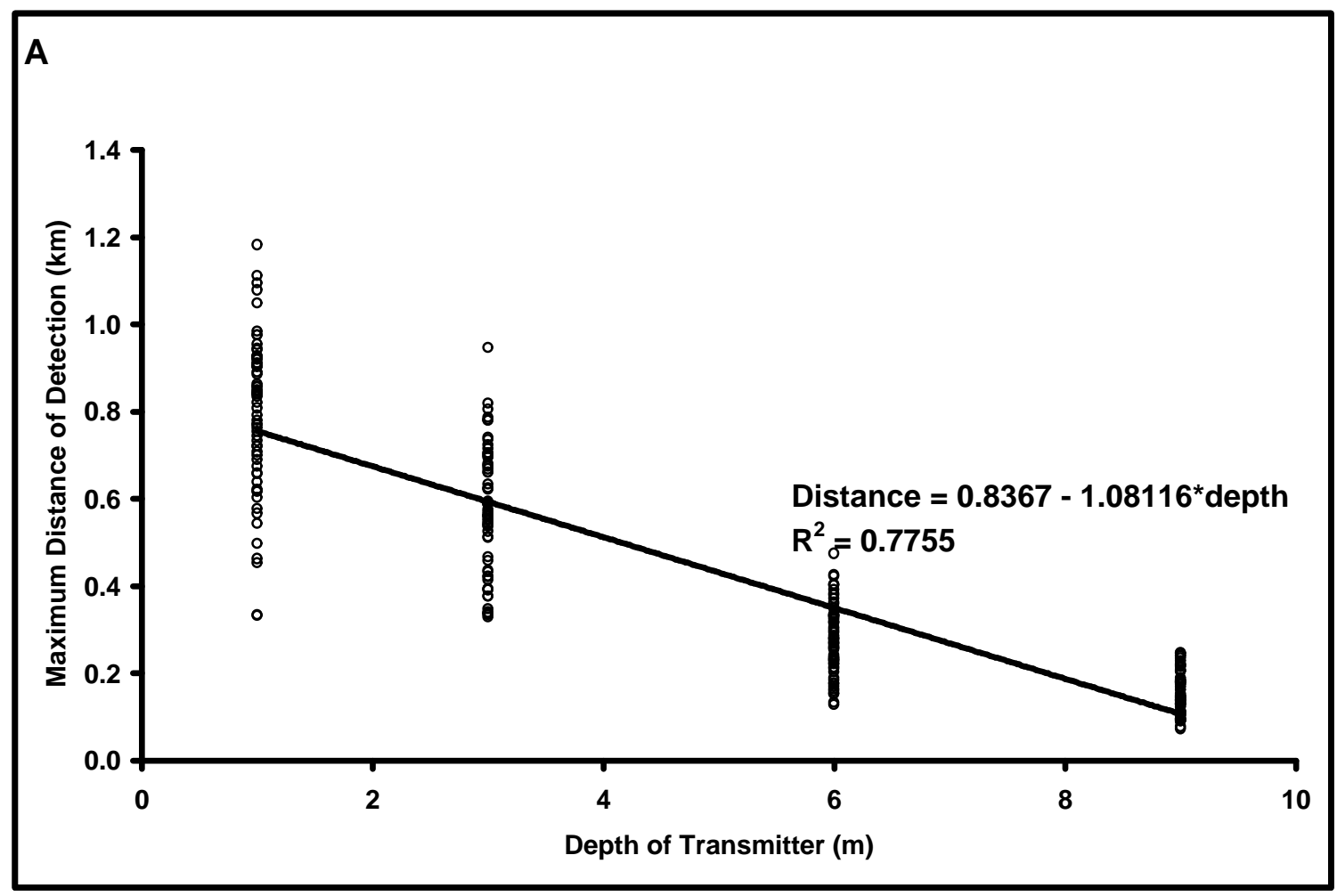

B

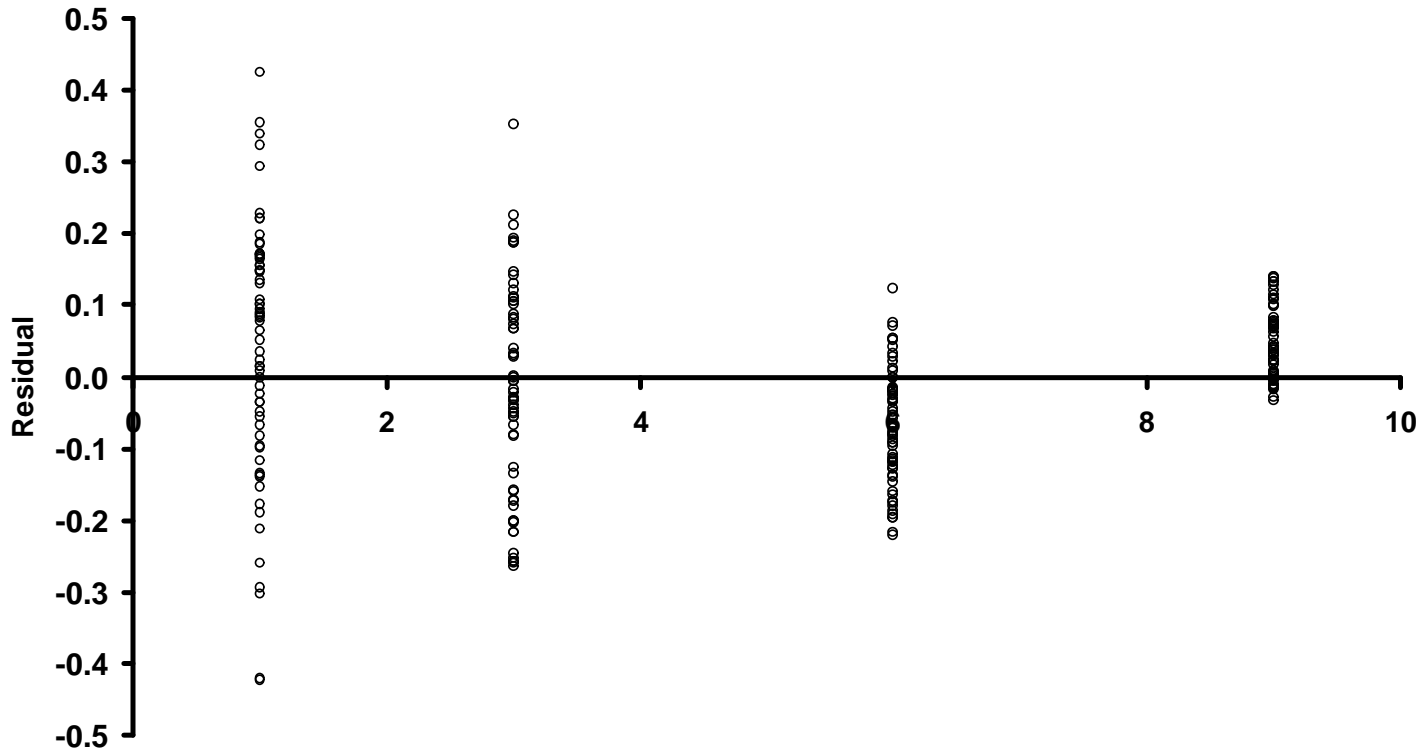

Depth of Transmitter (m) 
Figure 3. Non-linear relationship between maximum distance of signal detection at given transmitter depths $(\operatorname{Pr}(>\mathrm{F})=0.0001)$. The regression coefficient of the linearized equation: $\mathrm{LN}($ distance $)=\mathrm{á}^{\prime}-\hat{\mathrm{a}} *$ depth was 0.8307 .

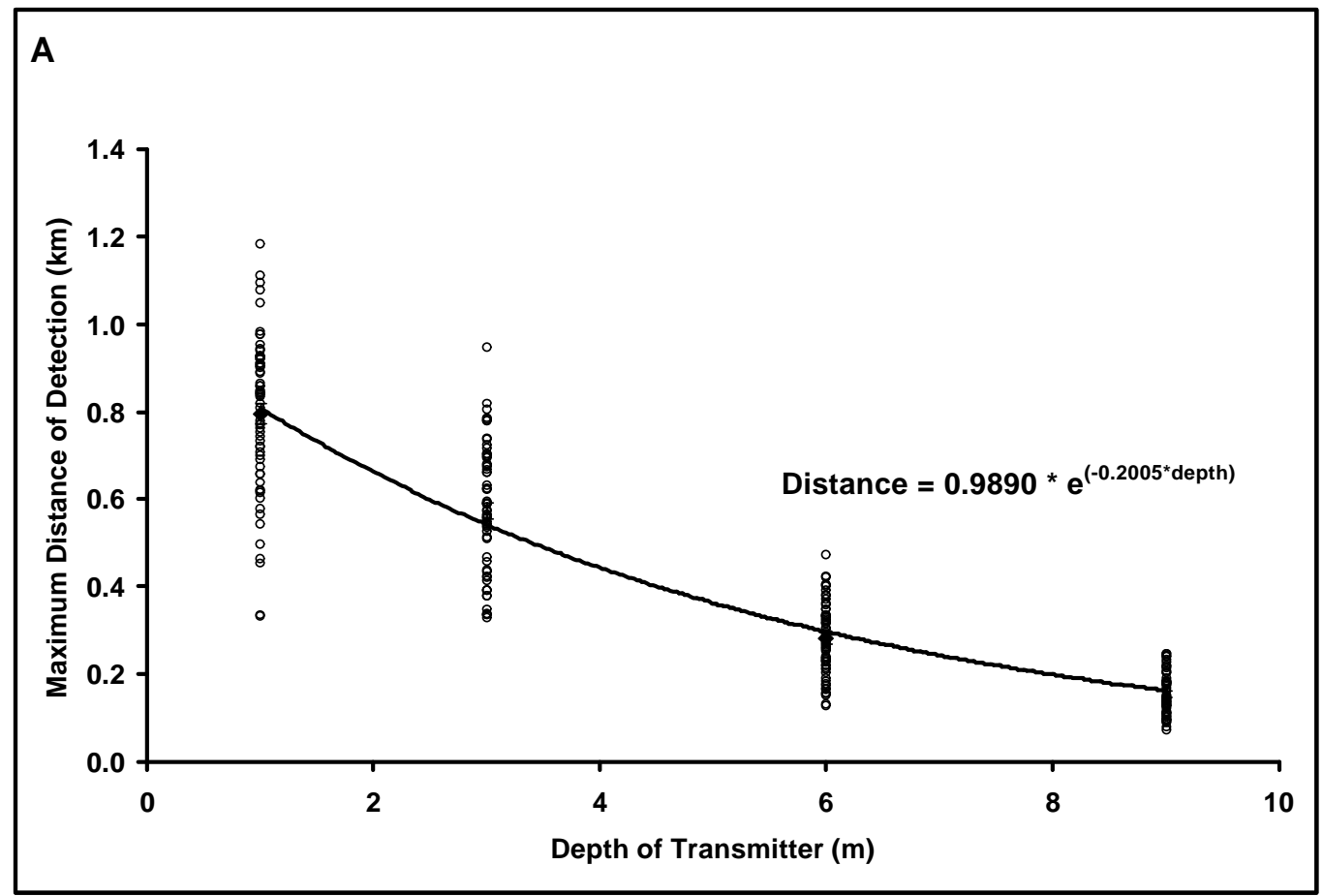

B

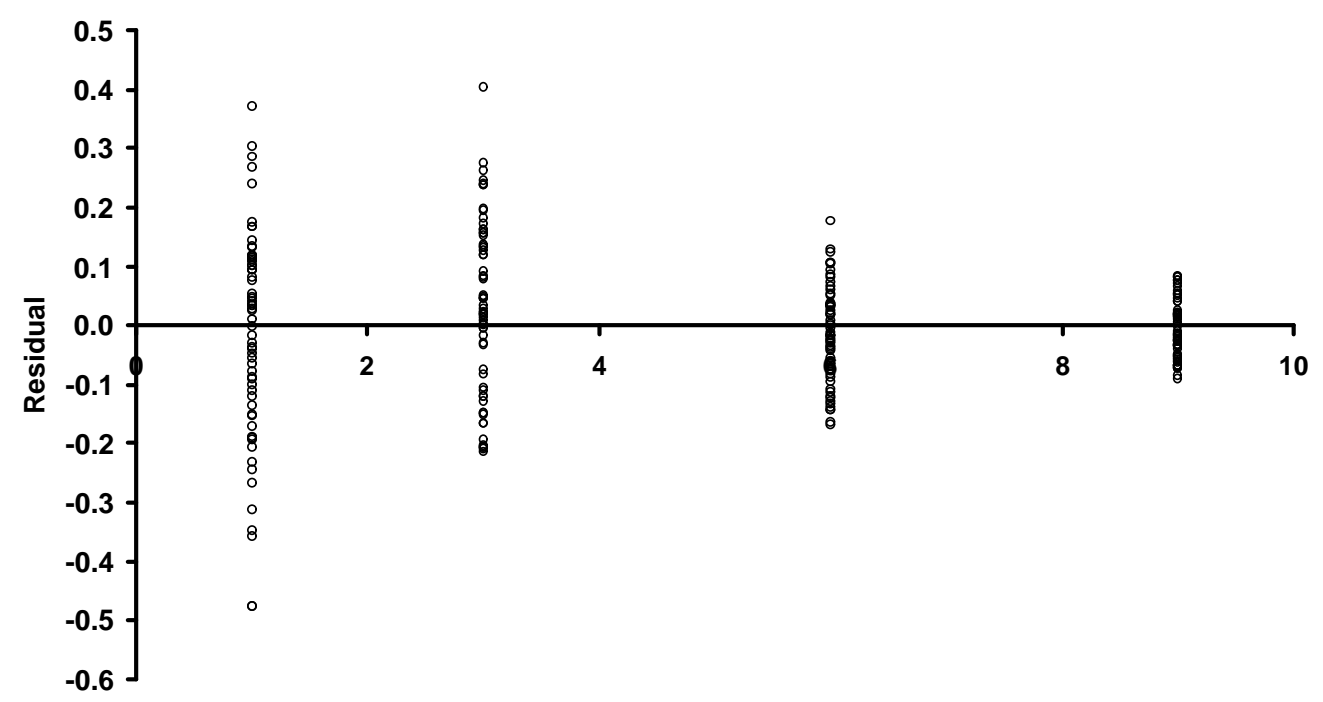

Depth of Transmitter (m) 


\title{
Chapter 3: Seasonal movement and macro-habitat use of largemouth bass (Micropterus salmoides) in an Ohio River navigation pool.
}

\begin{abstract}
Largemouth bass (Micropterus salmoides) provide an important sport fishery in much of the United States and declines in their populations, whether real or perceived, have important social, if not biological impacts. Off-channel areas are important in other large river systems, however it is uncertain how largemouth bass may use the relatively scarce off-channel areas in the Ohio River. Our objectives were to determine critical over-wintering and spawning habitats of largemouth bass in the Belleville Pool of the Ohio River. We surgically implanted radio-transmitters in 39 adult largemouth bass and tracked them over a 23-month period. Main river, tributaries, and embayments comprised $84.8 \%, 10.2 \%$, and $5.0 \%$ of the total surface area, respectively. However, $17.7 \%$ and $46.8 \%$ of all estimated fish locations were in tributaries and embayments, respectively. Differences in habitat use between main river and off-channel habitats were even more pronounced during spring and winter seasons where off-channel habitats comprised $75.8 \%$ and $60.3 \%$ of the recorded fish locations, respectively. Capture method may have strongly influenced how habitat use was perceived. Nevertheless, even for fish released in main river habitats, they used these habitats much less frequently than their availability would dictate. Our results, supported by the finding of studies on the Hudson River, Mississippi River, and Illinois River, demonstrate the importance of off-channel habitats in the life history of largemouth bass in large river systems. Sedimentation, resulting in a loss of embayment quality and surface area, is an important problem and thus merits increased attention. Restoration and protection efforts to improve largemouth bass fisheries in large river systems should be concentrated in embayment habitats.
\end{abstract}




\section{Introduction}

Within the Ohio River, as with much of the United States, largemouth bass (Micropterus salmoides) are an important fishery from a social and economic viewpoint. Largemouth bass are an important game fish throughout both their native and extensive naturalized range (Lee 1980). Revenue generated by anglers is very important to local economies (Schramm et al. 1991). Largemouth bass are often the top predators in many systems and declines in their populations may cascade to other trophic levels (Carpenter et al. 1987). Declines in largemouth bass populations, whether real or perceived, have important biological and social implications.

Large rivers altered for commercial navigation encompass both lotic and lentic characteristics, unlike reservoirs constructed for other purposes (Nielsen et al. 1986, Sheehan and Rasmussen 1999). Impounded large rivers retain characteristics associated with lotic environs such as a defined channel, a predictable biotic gradient (Vannote et al. 1980), and a hydrologic regime (Poff and Allan 1995, Poff et al. 1997). Conversely, long retention time, reduced current velocity, and the increase in pool volume along with the concurrent elimination of riffle habitats (Nielsen et al. 1986) are lentic characteristics associated with large, navigable rivers. Within a large, altered river, individual habitats may be distinctly lotic or lentic in nature, however the ecosystem cannot be accurately classified as either lotic or lentic.

The life history of largemouth bass in large river ecosystems has not been well documented. Due to the ambiguous nature of large, altered river systems, drawing conclusions from reservoirs, lakes, and unaltered rivers is tenuous at best. However, it is apparent that the impoundment of large river systems has dramatically increased the 
amount of largemouth bass habitat (Nielsen et al. 1986). Previous research has examined the importance of embayment habitats as over-wintering (Carlson 1992, Gent et al. 1995, Lehtinen et al. 1997, Raibley et al. 1997a), spawning, and nursery habitats (Sheaffer and Nickum 1986, Nack et al. 1993, Copp 1997, Raibley et al. 1997b) for largemouth bass in large river ecosystems. Despite genetic adaptations to cold water in northern strain largemouth bass (Fullerton et al. 2000), substantial over-winter mortality can occur in largemouth bass in the North (Carlson 1992, Gent et al. 1995, Raibley et al. 1997a).

Due to the relative scarcity and large variation in local climate, geology, land usage, and anthropogenic impacts, large river ecosystems are inherently variable. Consequently, management decisions based on research from other large river ecosystems are tenuous at best. For instance, the Mississippi River contains approximately twice the amount of backwater acreage per main channel surface acre than does the Ohio River (Nielsen et al. 1986). The Mississippi River flows essentially North to South accelerating the longitudinal gradient of biotic succession (Sheldon 1968). Main channel border habitats, important to many large river fishes (Abbe and Montgomery 1996, Lehtinen et al. 1997, Madejczyk et al. 1998), are limited within the upper and middle Ohio River due to the constricted nature of the river valley (Nielsen et al. 1986). While, the disconnection of the Ohio River from its floodplain is not unique (Sheehan and Rasmussen 1999), the loss of energy flow between the Ohio River and its floodplain may have a significant impact on the river's ecology (Kwak 1988, Junk et al. 1989). These differences accentuate the difficulties associated with applying research results from other large river ecosystems into management decisions. 
Despite a large literature base dedicated to largemouth bass behavior in large river ecosystems, the above-mentioned differences between large river ecosystems warrant research specific to individual large river ecosystems. Largemouth bass have been extensively studied in the Mississippi River (Pitlo 1992, Sheaffer and Nickum 1986, Gent

et al. 1995, Sheehan et al. 1994), Illinois River (Sheehan et al. 1994, Raibley et al. 1997a, 1997b), and the Tidal Hudson River (Carlson 1992, Nack et al. 1993). However, physical and geographical variation between these other river systems and the middle Ohio River suggests that results from other systems may not be applicable to the Ohio River, warranting research specific to that system.

The objectives of this study were designed to better understand the life history of adult largemouth bass in the Ohio River providing managers with information to make sound scientific decisions. The Ohio River constitutes an important sport fishery comprising roughly half of West Virginia's warm water surface acreage. The relative scarcity of embayment and main channel border habitats, which other research has identified as important habitat for largemouth bass, makes the Ohio River unique among large river systems. Our objectives were to determine over-wintering and spawning habitat of largemouth bass in the Ohio River as well as seasonal patterns of habitat use and movement.

\section{Methods}

\section{Study Site Description}

The Ohio River is formed by the confluence of the Monongahela and Allegheny Rivers in Pittsburgh, Pennsylvania. The river travels $2102 \mathrm{~km}$ before entering the Mississippi River near Cairo, Illinois (ORSANCO 1994). The Ohio River has been 
greatly altered by 20 United States Army Corps of Engineers (USACE) lock and dam structures that maintain a $3.7 \mathrm{~m}$ deep navigation channel (Figure 1). The Ohio River, formerly a shallow, braided river has been converted to a series of long, narrow impoundments and can no longer be considered riverine (Sheehan and Rasmussen 1989).

The Belleville Pool is created by the Belleville Lock and Dam at river kilometer 328.1 and is bounded upstream by the Willow Island Lock and Dam at river kilometer 260.2 (Figure 2). The $67.9 \mathrm{~km}$ long pool averages $404.5 \mathrm{~m}$ in width, $7.3 \mathrm{~m}$ deep and encompasses 2850 ha (ORSANCO 1994). Forty-five streams or rivers enter within the Belleville Pool including the Little Kanawha River and the Muskingum River, which are commercially navigable. The riparian zone is highly developed and industrialized, particularly in proximity to cities. The cities of Marietta, Ohio, located at the confluence

of the Muskingum River and Parkersburg, West Virginia, located at the confluence of the Little Kanawha River, comprise the largest population centers within the riparian zone.

\section{Macro-scale Habitats}

The Belleville Pool was divided into three very different functional macro-habitat units: embayment, tributary, and main river (Figure 3). Main river habitats encompass all aquatic areas between the respective shorelines. Main river habitats can be further divided into the main channel, main-channel border, and back-channels. The main channel habitats represent the thalweg and associated areas within the maintained navigation channel. The main-channel border is adjacent to the navigation channel and is typically shallow, current velocity is reduced, and is an area of sediment deposition. Back-channel habitats are outside of the thalweg and are formed by current breaks provided by an island. These areas generally have reduced current velocity and are better 
protected from waves caused by wind and barge traffic. Off-channel habitats are comprised of tributary and embayment habitats collectively. Local processes largely control ecological processes in off-channel areas though the connection to the main river does influence processes in off-channel areas. Embayments are created by the inundation of relatively small tributaries and typically resemble lentic habitats. Tributaries are relatively large inflowing streams that generally retain lotic characteristics upon impoundment.

\section{Seasonality}

Data were collected every month from July 1998 through June 2000 and were pooled into seasons for analysis. Seasons were divided into winter, spring, summer, and fall to correspond with seasonal changes in water temperature and largemouth bass behavior. The winter period spanned December through March and was defined by cold water temperatures and relatively little largemouth bass activity. April through June comprised the spring period, which was defined by increases in water temperatures and largemouth bass activity. The spring period represents largemouth bass pre-spawn and spawning phases. Summer (July through September) water temperatures are generally the warmest of the year and largemouth bass activity depends upon water temperature. October and November composed the fall period, which was characterized by a cooling of water temperatures creating a transition from warm summer temperature to colder winter water temperatures. Although these categories were determined subjectively, we felt our categorizations most simply and accurately captured the seasonal variability in water temperature and bass behavior. 


\section{Radio-Telemetry Methods}

\section{Radio Transmitters}

Low frequency transmitters weighing no more than $2 \%$ of the fish's body weight (Winter 1996) were implanted into the abdominal cavities of largemouth bass. Three sizes of transmitters manufactured by Advanced Telemetry Systems were used. The smallest of the transmitters weighed $8 \mathrm{~g}$ and were programmed with an on-off cycle of 12 hours and a minimum life expectancy of 150 days. The $11 \mathrm{~g}$ "medium" transmitters had an on-off cycle of 12 hours and a minimum life expectancy of 300 days. The largest of the transmitters weighed $17 \mathrm{~g}$, had a minimum life expectancy of 300 days, and were continuously on. Minimum fish weight for the small, medium, and large transmitters were $400 \mathrm{~g}, 550 \mathrm{~g}$, and $850 \mathrm{~g}$, respectively.

\section{Fish Capture Procedure}

The initial study design required equal numbers of fish to be captured from each of the three macro-habitat units with a boat electrofisher. However, very low electrofishing success, particularly in the main river and tributaries habitats did not allow implementation of a stratified design. Additionally, electrofishing sufficient numbers of largemouth bass in which the radio transmitter would comprise no more than $2 \%$ of their body weight (Winter 1996) was only possible while largemouth bass were staging to spawn or spawning. Consequently, we were forced to abandon our initial stratified design in which all fish to be implanted were to be captured via electrofishing.

Largemouth bass were collected for radio transmitter implantation by pulsed-DC boat electrofishing or were captured by angling (Tables 1, 2, and 3). Fish collected via angling were obtained from bass tournament anglers and were held in aerated livewells 
until they were brought to the weigh-in session. At the weigh-in session, fish were weighed and measured by tournament organizers. Only fish that were considered to be in good physical condition were implanted with radio transmitters. Fish selected for transmitter implantation were held in aerated water until the surgery procedure was initiated. Fish collected via electrofishing were held for a short period of time in the boat's aerated livewell ( $<15$ minutes) before the surgical procedure was initiated.

\section{Surgical Methods}

All procedures followed animal care and use protocols developed by West Virginia University (ACUC \#9806-04). Prior to surgical procedures, fish were anesthetized using commercially available food grade clove oil. A solution of $1.2 \mathrm{~mL}$ of clove oil dissolved in $12 \mathrm{~mL}$ of ethanol (Anderson et al. 1997) was dissolved in 20L of water. Fish were held in anesthetic solution until they lost their equilibrium at which time they were prepared to enter surgery.

Transmitters were surgically implanted into the abdominal cavity following procedures modified from Hart and Summerfelt (1975). Fish were placed on a surgical table modified from Courtois (1981). The surgical table was partially immersed in 20L of water aerated by a small, battery-powered recirculating pump to insure aerated water continuously flowed over the anesthetized fish's gills. Surgical equipment and transmitters were soaked in a sanitized stainless steel container containing a solution of Nolvasan $^{\circledR}$ and distilled water. A lateral incision slightly larger than the diameter of the transmitter was made anterior and dorsal to the anal vent and the transmitter was inserted through the incision. A straight needle with the transmitter antenna threaded through the eye of the needle was used to extend the antenna outside of the fish's body. A grooved 
receiver protected internal organs from the needle (J. Pitlo Jr., Iowa Department of Natural Resources, personal communication). After the antenna was extended from the body and the transmitter was inserted in the abdominal cavity, the incision was closed with three to five non-absorbable sutures. Surgery duration varied from three to eight minutes.

Recovery procedure varied slightly between tournament-caught bass and fish collected by electrofishing. Fish collected by electrofishing were recovered in 20L of water aerated by a small, battery-powered pump. Upon gaining equilibrium, fish were released near their point of capture. Fish collected via angling tournaments were recovered in large, aerated tanks provided by tournament organizers. Tournament collected largemouth bass were either released at the boat launch where the tournament weigh-in occurred or fish were transported in an aerated boat livewell to either a single or multiple release sites depending upon the desires of tournament organizers.

\section{Tracking Procedures}

Radio tagged bass were tracked by boat using an Advanced Telemetry Systems model 2000 scanning-type receiver. A $3.1 \mathrm{~m}$ tall by $3.7 \mathrm{~m}$ long four-element Yagi antenna was used in main river habitats to search for individual frequencies. A small hand-held loop antenna was used in embayment and tributary habitats where obstacles to navigation (e.g. culverts, overhanging canopy) did not allow the use of the large Yagi antenna. In all habitats, the loop antenna was used to obtain more accurate triangulation of the fish's estimated position. A search effort consisted of two days and we attempted to locate active signals weekly. More intensive efforts were committed during the spring and winter season to meet the primary objectives of the study. The main river and tributaries 
in which the large antenna could be used were tracked on separate days from the embayments and tributaries that required the use of the smaller loop antenna.

Upon detection of a radio frequency, the boat was positioned at a point, usually 50 $\mathrm{m}$ or greater from the fish, where its presence would not interrupt the behavior of the fish. The location of the boat's position was recorded with a Garmin ${ }^{\circledR} 12 \mathrm{X}$ GPS. The location of each fish was determined by standard triangulation methods (Samuel and Kenow 1992) using a hand-held loop antenna. A null-peak, a lack of a detectable telemetry signal, indicated the direction to a fish's position and this direction was recorded from a compass. Triangulation error was considered to be unimportant since it was substantially smaller than the macro-habitat units. Under no circumstances would the triangulation error provide a false reading of the macro-habitat unit used. Macro-habitat unit was recorded during the estimation of the fish's location. Fish locations obtained within 10 days of surgical implantation were not included in analysis as fish have been shown to move erratically following surgery (Mesing and Wicker 1986, Winter 1996). Additionally, locations of two fish were removed after they were known to have died or expelled transmitters. Since the date of mortality or transmitter expulsion was uncertain, these two fish were removed from all analyses.

\section{Water Quality Measurements}

Water quality measurements were taken during with radio telemetry searches of the embayments and tributaries. Dissolved oxygen was measured to the nearest $0.1 \mathrm{mg} / \mathrm{l}$, temperature was recorded to the nearest $0.1{ }^{\circ} \mathrm{C}$, conductivity to the nearest $0.1 \mathrm{i} S$, and turbidity was recorded to the nearest $1.0 \mathrm{NTU}$. Water quality measurements were collected at 20 stations throughout the lower half of the Belleville Pool at a depth of $1 \mathrm{~m}$ 
below the surface. Data were collected from seven embayment and three tributary

habitats. Each embayment and tributary had a corresponding main river station that was situated at least $100 \mathrm{~m}$ from the shore and away from the immediate influence of any tributary, embayment, and industrial or municipal outflow. All water quality measurements were recorded using a Yellow Springs Instruments model 3800 water quality logger.

\section{Statistical Analysis}

Macro-habitat units were tested for seasonal differences between water quality measurements using an analysis of variance (ANOVA). A seasonal mean for each water quality measure was calculated for each sample location. To determine if water quality parameters differed seasonally between habitats the error term location within year was used to test the interaction of seasons and years. Upon detection of a significant ANOVA, a post-hoc Tukey-Kramer test on least square means, adjusted for unequal sample sizes, was used to make meaningful comparisons between habitats, seasons, and habitats within seasons. Tests between different habitats in different seasons were considered to be extraneous and of no biological relevance. An alpha level of 0.05 was selected for all statistical hypothesis tests.

Macro-scale habitat use, as assessed by telemetered fish locations, was compared to habitat availability using chi-square analysis. Availability of macro-scale habitat units was obtained from a geographical information system (GIS) encompassing the Belleville Pool compiled by the West Virginia Natural Resource Analysis Center (NRAC) at West Virginia University. While triangulating the fish's location in the field the macro-habitat unit the fish was occupying was determined. Chi-Square tests were conducted for each 
season and for the collective data set to determine general and seasonal differences in habitat selection compared to availability. The Chi-Square tests ( 2 d.f.) were compared to a critical value of 5.991. The Chi-Square value attributed to each habitat and the proportion of the Chi-square test statistic they comprise explains their relative contribution to the Chi-Square test statistic. Additionally, Chi-Square analysis was used to determine the influence and relative contribution of capture method on habitat use.

\section{Results}

\section{Telemetered Fish}

Thirty-nine wild-caught largemouth bass were captured and implanted with radio transmitters from 02 July 1998 through 09 May 2000 (Tables 1, 2, and 3). These 39 fish were located by radio telemetry 357 times (Table 4). Of these 39 fish, 28 were located at least once while the remaining 11 were never located or were removed from analysis due to mortality or transmitter expulsion. On average, each transmitter was located 11.9 times (95\% CI: $11.9 \pm 3.4)$ over an average period of 155.8 days (95\% CI: $155.8 \pm$ 42.3). To meet the primary objectives of our study, 22 fish were followed during the winter period and 23 fish were tracked during the spring period, including two fish that were tracked during two consecutive springs.

Macro-scale habitat use was significantly different than macro-scale habitat availability with fish tending to differentially select embayments over other habitats (Table 5, Figure 4). The main river habitats comprise $84.8 \%$ of the total surface area of the Belleville Pool with back-channel areas comprised $12.4 \%$ of the total area of the Belleville Pool and $14.6 \%$ of the main river surface area. Off-channel habitats comprise the remaining $15.2 \%$ of the total Belleville Pool area. Of this, embayments make up 
$33.0 \%$ of the off-channel area and $5.0 \%$ of the total Belleville Pool surface area and tributaries comprise the remaining $67.0 \%$ of the off-channel acreage and $10.2 \%$ of the total Belleville Pool surface acreage. However, $46.8 \%$ of all recorded fish locations were in embayment habitats. Tributaries comprised $17.7 \%$ of all fish locations with main river habitats comprising the remaining $35.6 \%$ of the radio telemetry locations.

Macro-habitats were used disproportionately to their availability over the entire study and during each season (Table 5, Figure 5). Disproportionate use of habitats was most pronounced during the winter and spring seasons (Figure 5), evident by the large proportion of the significant Chi-Square test statistic they contributed (Table 5). Overall, embayments contributed $91.1 \%$ of the total Chi-Square test statistic indicating they are responsible for most of the difference between habitat use and availability. Embayments comprise $47.8 \%$ of spring fish locations (Figure 5a) and contribute approximately $83 \%$ of the Chi-Square test statistic for the spring season (Table 5) and $44.5 \%$ of the winter fish locations (Figure 5b) and contribute $92.0 \%$ of the winter Chi-Square test statistic (Table 5).

Very low electrofishing success in main river and tributary habitats forced an abandonment of a stratified design where equal number of fish were collected from each macro-habitat unit. Seventeen of eighteen fish captured via electrofishing were collected and released in embayment habitats (Table 2). We were rarely able to acquire capture locations for fish obtained from competitive angling tournaments. Of the four largemouth bass obtained from tournaments in which capture location was ascertained, three were captured in main river habitats and the remaining fish was captured in an 
embayment (Table 2). All tournament obtained fish were released into main river habitats except for one fish that was released in a tributary (Table 3).

Our perception of habitat use of largemouth bass was largely affected by capture method (Table 6). Fish captured via electrofishing used embayments much more heavily than would be expected due to their availability (Table 6). Despite this possible bias, our results indicate a sub-population of largemouth bass extensively use embayment habitats evident by the $84.7 \%$ of locations for fish captured by electrofishing that were in embayment habitats. However, for fish captured via angling, 55.3\% of fish locations were in main river habitats but a significant proportion of fish locations (46.7\%) were located in off-channel habitats, particularly in the spring and winter. Tributary habitats were used more extensively by fish obtained by angling, contributing $79.8 \%$ of the total Chi-Square test statistic.

\section{Observed Fish Behavior Patterns}

The case studies of two fish are presented to best illustrate the general patterns of movement and seasonal habitat use of largemouth implanted with radio transmitters during our study. Two general patterns of dispersal were evident among the radio tagged bass, which we termed "movers" and "home-bodies" (Figures 6 and 7). Fish implanted with frequencies of 48.082 MHz (Fish 48.082) and 49.230 MHz (Fish 49.230) illustrate these general patterns. These two particular fish were selected due the relatively large amount of radio telemetry positions collected over a long period of time and their movements are representative of the general dispersal and habitat use patterns observed for other largemouth bass during our research. Fish 48.230 was captured via electrofishing in the Lee Creek embayment during the summer of 1998 and was among 
the first fish implanted with a radio transmitter during the study (Table 1, 2, and Figure 6). Fish 48.082 was captured by a tournament-angler during a mid-September 1999 tournament in Parkersburg, WV. After being implanted with a radio transmitter, the fish was transported in an aerated boat livewell and released along the Blennerhasset Island shoreline in a back-channel habitat (Table 2, Figure 8).

Fish 49.230 (Figure 6) was classified as a "home-body", having been located within the Lee Creek embayment on 35 of 36 occasions. Within the Lee Creek embayment, the fish occupied a large home range (Figure 6, Sites A, B, and C) except when it was relatively immobile during the spring, coinciding with spawning behavior (Site B). All summer locations were within Lee Creek (Figure 6, Sites A and B) and movement increased during the fall (Figure 6, Sites A, B, and C). During December of 1998, this fish moved from Lee Creek (Figure 6, Site C) into the Ohio River (Figure 6, Site D) and utilized a large submerged tree in the main channel border. During this time, water temperature in Lee Creek dropped (in response to a sudden cold weather pattern), falling below the temperature of the main river, which was moderated due to its larger volume. However, after the initial water temperature change in the embayment, the main river temperature again became consistently colder than the embayment. After the river became colder than Lee Creek, the fish returned to the embayment where it maintained the same "home-body" dispersal pattern it had exhibited before moving from the embayment. Similar patterns were experienced in December of 1998 with two other fish implanted with transmitters frequencies of 49.428 (Fish 49.428) and 49.457 (Fish 49.457). Fish 49.428 moved from Lee Creek sometime between 29 November 1998 and 14 December 1998 when it was located in the main river near the mouth of Lee Creek 
before again returning to Lee Creek and remaining there until the transmitter expired. Fish 49.457 displayed a very similar pattern moving between the Swan Run embayment and the main river in mid-December 1998. All spring 1999 locations of fish 49.230 were in close proximity (Figure 6, Site B) and the fish exhibited spawning behavior (remained at or near the same location for an extended period of time during the spring) before the transmitter expired in mid-May.

Fish 48.082, a "mover", used a greater variety of habitats, exhibited a relatively large spawning migration in late winter and early spring, and dispersed greater distances than fish 49.230 (Figure 7). After being released in the Blennerhasset Island back-channel, it moved downstream and took up residence in the Sand Creek embayment. The fish was located in a small unnamed embayment in Ohio (Figure 7, Site A) on one occasion before reaching Sand Creek (approximately $11.4 \mathrm{~km}$ downstream of the release site) where it spent the remainder of the fall and most of the winter (Figure 7, Site B). Within Sand Creek, this fish was reliably located within a small home range. Between 26 February 2000 and 30 March 2000 fish 48.082 moved approximately $29 \mathrm{~km}$ from its overwintering location in Sand Creek to the Little Kanawha River (Site C). During the spawning migration to the Little Kanawha River the fish was not located during radio telemetry searches indicating the possible use of deep-water habitats (See Chapter 2). Fish 49.082 was located in the Little Kanawha River until the battery expired in mid-June 2000. The fish was located in the same location in the Little Kanawha River on three occasions (Site D) in mid-May through early-June where it was presumed to have spawned. During the spring season, the fish moved upstream approximately $1.4 \mathrm{~km}$ on 01 June 2000 but returned (Site D) on 5 June 2000. An angler reported catching Fish 
48.082 from its spawning nest and noted that it was on a nest, was in good health, and the surgical incision had healed well.

\section{Water Quality}

Differences in water quality parameters between macro-habitats were examined over several spatial and temporal scales. Temperature of macro-habitat units differed within seasons (ANOVA, $\mathrm{P}<0.0001$ ) and between seasons (ANOVA, $\mathrm{P}<0.0001$ ). Posthoc analysis determined that temperature differed significantly between all seasons but did not differ between habitat units when temperature was pooled over all seasons. Winter water temperature in the main river was colder than was the tributary and embayment water temperatures, which were statistically undifferentiated. During fall, the next coolest season, temperatures of embayment and tributary habitats were similar and were significantly cooler than the main river. Water temperatures during the spring and summer were not significantly different among the three macro-habitat units. Changes in the relative temperature between habitat units over different seasons were the most likely reason temperatures did not differ between habitat units for the pooled data set. Low statistical power did not permit comparisons between individual tributary, embayment, and main river water quality sampling locations.

Turbidity differed between seasons (ANOVA, $\mathrm{P}<0.0001$ ), macro-habitats (ANOVA, $\mathrm{P}=0.0121$ ), and macro-habitats within seasons (ANOVA, $\mathrm{P}=0.0005$ ). Turbidity was highest in embayments, followed by tributaries, and then main river habitats. Summer turbidity was greater than spring and fall turbidity, which did not differ statistically. Relatively consistent patterns emerged within seasons. Turbidity during the fall was greatest in embayment habitats while main river and tributary habitats did not 
differ. Turbidity in the spring was lowest in main river habits while tributary and embayment habitats did not differ statistically. Turbidity measured during the summer was highest in embayment habitats while main river and tributary turbidity did not differ.

Tests for differences in DO and conductivity were less informative than were tests for temperature and turbidity. Conductivity differed between seasons (ANOVA, $\mathrm{P}<0.0001)$ but not between macro-habitats, and more importantly, differences between macro-habitats within seasons were not evident. Conductivity was greatest during the summer and fall seasons. DO was statistically different between seasons (ANOVA, $\mathrm{P}<0.0001$ ), but not between macro-habitats or macro-habitats within a season. Measured DO varied between all seasons with winter having the highest DO and summer the lowest. The lowest recorded DO measured was $3.9 \mathrm{mg} / \mathrm{L}$ in Sand Creek in June of 1999 and mean DO concentration across all samples was 10.7mg/L (95\% CI: 10.5-11.0).

\section{Discussion}

\section{Seasonal Habitat Use}

Off-channel habitats are of critical importance as spawning and over-wintering habitats to largemouth bass in the Belleville Pool of the Ohio River. While tributaries and embayments comprised only $10.2 \%$ and $5.0 \%$, respectively, of the total Belleville Pool surface area, they accounted for $17.7 \%$ and $46.8 \%$ of all fish locations obtained from our radio telemetry study. Seasonally, this discrepancy is even more evident with $60.3 \%$ of winter fish locations and $75.7 \%$ of spring fish locations observed in off-channel habitats. Our conclusions are supported by research on other large river systems including the Mississippi River (Sheaffer and Nickum 1986, Pitlo 1992, Sheehan et al. 
1994, Gent et al. 1995,), Illinois River (Sheehan et al. 1994, Raibley et al. 1997a, 1997b), and Hudson River (Carlson 1992, Nack et al. 1993).

\section{Spawning}

Seasonal habitat selection was most evident by the disproportionate use of offchannel habitats during the spring coinciding with largemouth bass spawning. Our experiences, supported by previous research (Mesing and Wicker 1986, Nack et al. 1993, Raibley et al. 1997b), suggest that largemouth bass selected off-channel areas because they warm earlier than main channel habitats (Mesing and Wicker 1986, Nack et al. 1993) and they offer protection from wind and waves (Nack et al. 1993, Raibley et al. 1997b). In the Belleville Pool, tributaries and embayments comprise only $10.2 \%$ and $5.0 \%$ of the available surface acreage but $27.9 \%$ and $47.8 \%$ of all telemetered fish locations during the spring season, respectively, were located in these habitats.

Largemouth bass typically select spawning sites that protect the nest from wave action created by wind, tides, or barges (Mesing and Wicker 1986, Bruno et al. 1990, Nack et al. 1993). In Florida lakes, largemouth bass nests were associated with vegetation (Bruno et al. 1990) or were in vegetated canals (Mesing and Wicker 1986), both of which protect nests from wave action. In the Ohio River, off-channel areas may protect largemouth bass nests from waves caused by passing barges that increase suspended solids and create waves that may leave a nest temporarily dewatered causing its failure (Hershfeld et al. 1986, Nielsen et al. 1986). Nack et al. (1993) observed largemouth bass selecting spawning areas that were protected from tidal fluctuations. Although approximately $63 \%$ of the Hudson River shoreline within their study area was exposed, only $1 \%$ of the largemouth bass nests visually located were in these areas. The 
majority of largemouth bass nests were located in bays (44\%), creek mouths (37\%), and coves $(18 \%)$. A similar pattern emerged in our study with $75.7 \%$ of spring fish locations being observed in off-channel habitats despite the relative scarcity of these more protected habitats.

Off-channel habitats are important as spawning habitat in large river systems as evidenced by our research, which is further supported by research in other large river systems (Nack et al. 1993, Raibley et al. 1997b). Embayments and tributaries, reduced in volume compared to the main channel are quicker to warm in the spring (Nack et al. 1993, Raibley et al. 1997b). Difference in temperatures between habitats as small as 1.0 to $2.7^{\circ} \mathrm{C}$ may be enough to stimulate spawning site selection (Mesing and Wicker 1986). Similarly, Ohio River embayments and tributaries were warmer earlier than the main channel. Except for one bass that exhibited spawning behavior in a main river backchannel, all spawning activity of telemetered bass in our study occurred within embayment and tributary habitats.

Embayment and tributaries appear to be important spawning areas for largemouth bass. All radio tagged fish that migrated prior to the spawning season, moved into embayment or tributary habitats. For instance, fish 48.082 migrated approximately 29 $\mathrm{km}$ from its wintering location to the Little Kanawha River where it was observed spawning. This was within the range of dispersal witnessed for radio tagged largemouth bass in the tidal Hudson River that dispersed 1.6 to $64.0 \mathrm{~km}$ to reach spawning areas (Nack et al. 1993). Similar behavior was observed for other radio-tagged largemouth bass in the Ohio River with fish generally moving to, or remaining in, off-channel habitats to spawn. 
Two fish were followed over two consecutive springs showing spawning site fidelity by spawning in the same embayment each spring. Fish 49.014 was always observed in the Lee Creek embayment and spawned in both springs in different locations within the embayment. The second fish, implanted with a frequency of $49.095 \mathrm{MHz}$, spawned both springs in the Sugar Camp Run embayment. In the spring of 2000, the fish moved approximately $3.3 \mathrm{~km}$ from the Indian Run embayment to return to Sugar Camp Run to spawn.

\section{Over-Wintering}

Ohio River off-channel habitats were heavily used by wintering largemouth bass, similar to conclusions drawn from other large river systems, such as the Illinois River (Raibley et al. 1997a), Hudson River (Carlson 1992), and the Mississippi River (Pitlo 1992, Gent et al. 1995). Largemouth typically select over-wintering habitats that have relatively warmer temperatures and lower current velocity when DO is sufficient (Pitlo 1992, Gent et al. 1995, Raibley et al. 1997a). Bass followed during our study were concentrated in off-channel habitats during the winter. In the freshwater section of the tidal Hudson River, 58\% of largemouth bass used one of five known wintering sites that provided tidal refugia (Carlson 1992). Research on the Illinois River (Raibley et al. 1997a) and Mississippi River (Pitlo 1992, Gent et al. 1995) showed an even more pronounced use of off-channel habitats. Typically, largemouth bass that over-wintered in the main channel of the Ohio River were located in island back-channels or near thermal inputs. Of the 58 main river fish locations during the winter, $51.7 \%$ of fish locations obtained during the winter in main river habitats were located in back-channel $(20.7 \%)$ or near industrial thermal discharges $(31.0 \%)$. 
Movement of largemouth bass to over-wintering habitats and movement in response to thermal changes in over-wintering areas played a key role in the wintering ecology of Ohio River largemouth bass. For instance, fish 49.082 moved $11.5 \mathrm{~km}$ from its release site to where it over-wintered in the Sand Creek embayment. Unfortunately, since the fish was captured at an angling tournament, it is impossible to know if its dispersal to Sand Creek was a homing behavior as exhibited by other tournament caught fish (Klindt and Schiavone 1991, Richardson-Heft et al. 2000) or the fish moved randomly until it found suitable habitat. This movement, and that of other fish in our study are similar to those reported by Pitlo (1992) whom witnessed largemouth bass moving up to $14.5 \mathrm{~km}$ in the Mississippi River channel to access over-wintering habitats.

Bass appeared cognicent of more optimal thermal conditions in areas outside the macro-habitat they were occupying. Specifically, movement of radio tagged largemouth bass from wintering areas in embayments into main river habitats occurred in our study in December of 1998 in response to relatively colder embayment temperatures and warmer main river temperatures. Fish returned to embayments when these areas again offered warmer temperatures than the main river. Other researchers (Gent et al. 1995, Raibley et al. 1997a) experienced fish moving within backwater complexes but did not experience fish entering the main river when wintering in off-channel areas. Our results likely differ due to the relative simplicity and scarcity of Ohio River off-channel areas compared to Mississippi and Illinois River off-channel complexes as described by Gent et al. (1995) and Raibley et al. (1997a), respectively. The relative simplicity of Ohio River embayments does not provide fish with the opportunity to locate suitable over-wintering habitats without leaving the embayment during extreme thermal fluctuations. Pitlo 
(1992) suggested that lack of over-wintering refugia in the upper Mississippi River may limit centrarchid populations. These off-channel refuges are even more limited in the upper Ohio River (Nielsen et al. 1986).

\section{Water Quality Influences}

While other research concerning over winter habitat use of largemouth bass in large rivers has highlighted the significance of DO in habitat selection, hypoxia did not appear to be a problem in our study. The lack of strong influences of DO concentration on radio tagged largemouth bass behavior is not surprising given the Southerly location of our study site compared to other large river largemouth bass telemetry studies (Pitlo 1992, Carlson 1992, Gent et al. 1995, Raibley et al. 1997a). Concentration of DO greatly influenced winter fish distribution and over-wintering success in Mississippi River backwaters (Pitlo 1992, Gent et al. 1995, Knights et al. 1995) and Illinois River backwater lakes (Raibley et al. 1997a). The lack of winter hypoxia in Ohio River embayments experienced in the Mississippi River (Gent et al. 1995) and Illinois River (Raibley et al. 1997a) is due to the relatively strong connection between embayment and main river habitats and the lack of ice cover and the relative scarcity of decaying plant material. The lowest recorded DO reading was $3.9 \mathrm{mg} / \mathrm{L}$ well above levels other researchers found to influence fish behavior. Knights et al. (1995) radio tagged bluegill sunfish (Lepomis macrochirus) and black crappie (Pomoxis nigromaculatus) in Mississippi River backwater lakes concluding that fish did not avoid low DO concentrations until they were $2 \mathrm{mg} / \mathrm{L}$ or less.

Although turbidity was higher in embayment habitats than either tributary or main channel habitats, turbidity did not appear to deter largemouth bass from using 
embayments. However, high turbidity in embayments, related to elevated total suspended solids, may be indicative of long-term sedimentation problems. Sheehan and Rasmussen (1999) predicted that many Mississippi River backwater habitats may be lost due to sedimentation within the next 50-100 years. Sedimentation could lead to losses or long-term declines in the quality of embayment habitats that are critically important to over-wintering and spawning largemouth bass (Carlson 1992, Nack et al. 1993, Gent et al. 1995, Raibley et al. 1997a, 1997b).

\section{Research Bias}

Bias may have been introduced into the study through both fish collection bias and radio tag limitations. We were unable to capture largemouth bass in equal numbers for radio transmitter implantation in all habitat types. Capturing largemouth bass of sufficient size to implant with a transmitter was extremely difficult except during the spring in embayment habitats. While the method of capture, which was correlated to the macro-habitat of release, strongly influenced the perceived habitat use of radio tagged largemouth bass, important patterns did emerge. Of the 18 fish captured by electrofishing, none were captured in tributary habitats, one was captured in the main river, and the remaining 17 largemouth bass were captured in embayment habitats. Obtaining fish at competitive angling tournaments became necessary due to low electrofishing capture success. Tournament caught fish released into main river areas used main river habitats disproportionately low compared to their availability. These results suggest that a sub-population of largemouth bass use embayments nearly extensively. Another portion of the population may use main river habitats seasonally 
but move to off-channel areas particularly to access spawning and over-wintering habitats.

Unfortunately, we were unable to determine if tournament caught largemouth bass displayed homing behavior after being implanted with a radio transmitter. The inability to obtain capture locations for bass obtained at bass tournaments made it was impossible to determine if tournament caught largemouth bass returned to their original home range or dispersed into other suitable habitats (Klindt and Schiavone 1991, Richardson-Heft et al. 2000). Additionally, except for one fish, all tournament-caught bass implanted with radio transmitters were released into main river habitats, possibly inflating our estimates of largemouth bass utilization of main river habitats.

The difference in delectability among radio signals originating from shallow and deep water may have been introduced a substantial bias (Stasko and Pincock 1977, Otis and Weber 1982, Freund 2001). After noticing several occasions where a radio frequency was not detected during one week's telemetry search, but was later detected we conducted an experiment to examine the possible importance of increased signal attenuation in deep water. Our results demonstrated that the distance of maximum detection declined exponentially with the depth of the transmitter within the water column (see chapter 2). This reduced ability to detect transmitters in deeper water may lead to the underestimation of fish using deepwater habitats. Other researchers have addressed this issue. For instance, Mesing and Wicker (1986) considered their estimate that 8 of 22 radio tagged largemouth bass were located in open water to be conservative since there were many occasions when these 8 fish and others were not detected during their search efforts. Further evidence is provided in our study by two fish that were 
tagged and not located again, from 10 days post tagging until 235 and 287 days post tagging. Previous research within the Ohio River with striped bass (Morone saxatilis, Henley 1990) and hybrid striped bass (M. saxatilis x M. chrysops; Vallaza 1995) revealed that fishes typically followed the trench formed by the intersection of the shoreline slope and navigation channel. If largemouth bass use similar features to guide long-distance dispersals, fish may have been deep and less likely to be detected by radio telemetry equipment during dispersal events (Stasko and Pincock 1977, Otis and Weber 1982, Freund 2001).

Lack of mortality sensors in our tags prevented the accurate assessment of mortality. Mortality of a fish was more likely to be detected in embayment and tributary habitats than in main river habitats as a lack of movement was more easily detected in the smaller embayment and tributary habitats (personal observation). To reduce the probability of including dead fish in research results, we recommend mortality sensors, if possible. To reduce this potential bias, we removed all locations of fish that died or expelled transmitters since we were unable to ascertain the date at which death or tag loss occurred.

However, these biases are not unique to this study and were unavoidable. Conclusions based on our data that suggest the importance of off-channel habitats is in agreement with previous research in other large river systems (Carlson 1992, Pitlo 1992, Nack et al. 1993, Gent et al. 1995, Raibley et al. 1997a, 1997b).

\section{Management Recommendations and Future Research}

Management of large river navigation pool fisheries is wrought with difficult decisions, a lack of information concerning biological processes in these highly altered 
systems, and an inability to implement these management decisions. Among the largest problems facing managers of large river fisheries are human impacts and their incompatibility with fisheries (Sheehan and Rasmussen 1999). Historically, management decisions for large rivers maintained for navigation have been centered on the needs of commercial navigation. Fisheries managers entered the decision-making processes too late to have a legitimate voice in large river management decisions (Sheehan and Rasmussen 1999). This lack of influence in decision-making processes coupled with the inherent difficulty in sampling large river systems creates a situation where forming and implementing biologically sound management decisions is difficult at best.

Off-channel habitats, embayments in particular, are vital over-wintering and spawning habitats for largemouth bass in the Ohio River. The scarcity of off-channel habitats in the upper Ohio River coupled with their importance as over-wintering and spawning habitats warrants that greater emphasis be placed on maintaining and restoring these vital habitats.

Management efforts for Ohio River largemouth bass should focus on restoration and protection of embayment habitats. While embayment habitats cannot be separated from the main river, restoration and protection of the relatively small embayment habitats is likely more feasible economically. Among the most important processes negatively affecting embayment habitats is sedimentation (Sheehan and Rasmussen 1999). Sedimentation of embayment habitats could be reduced by improved land use practices including the protection and restoration of embayment riparian areas. Researchers on other large river systems have also suggested that largemouth bass management focus on the protection and restoration of backwater or embayment habitats (Carlson 1992, Nack 
et al. 1993, Gent et al. 1995, Raibley et al. 1997a, 1997b). Restoration efforts on the Mississippi River backwaters (Gent et al. 1995, Knights et al. 1995) have increased overwinter survival of centrarchids. A recent agreement between the U. S. Army Corps of Engineers and the West Virginia Division of Natural Resources that minimizes water level fluctuations during the largemouth bass spawning season may be an important first step in reducing human-induced impacts on the largemouth bass fishery (Nielsen et al. 1986, Raibley et al. 1997b).

The importance and popularity of the Ohio River largemouth bass fishery warrants future research into the biological impacts of angling on largemouth bass population size and structure. The peak of largemouth bass angler effort coincides with the largemouth bass spawning season on the Ohio River (personal observation). Nest success is greatly reduced by catch and release angling even when the fish is released within a relatively short period after its capture (Philipp et al. 1997). Fish removed from the nest and transported in tournament angler live wells have likely caused the total failure of that nest (Kieffer et al. 1995, Philipp et al. 1997). However, population level and size structure effects of catch-and-release and competitive angling are not well understood (Hayes et al. 1995, Philipp et al. 1997) necessitating additional research.

Our results should be used by resource managers to direct future research efforts and serve as a foundation on which to base management decisions. Our results suggest that off-channel habitats and embayments in particular are critical habitats that merit increased attention and protection by resource managers. These critical habitats are of even greater importance on the Ohio River where off-channel habitats are relatively scarce and may limit largemouth bass populations. 


\section{References}

Abbe, T. B. and D. R. Montgomery. 1996. Large woody debris jams, channel hydraulics and habitat formation in large rivers. Regulated Rivers: Research and Management 12:201-221.

Anderson, W. G., R. S. McKinley, and M. Colovecchia. 1997. The use of clove oil as an anesthetic for rainbow trout and its effects on swimming performance. North American Journal of Fisheries Management 17:301-307.

Bruno, N.A., R. W. Gregory, and Jr. H. L. Schramm, 1990. Nest sites used by radiotagged largemouth bass in Orange Lake, Florida. North American Journal of Fisheries Management 10: 80-84.

Carlson, D. M., 1992. Importance of wintering refugia to the largemouth bass fishery in the Hudson River Estuary. Journal of Freshwater Ecology 7:173-180.

Carpenter, S. L., J. F. Kitchell, J. R. Hodgson, P. A. Cochran, J. J. Elser, M. M. Elser, D. M. Lodge, D. Kretchmer, X. He, and C. N. von Ende. 1987. Regulation of lake primary productivity by food web structure. 68:1863-1876.

Copp, G. H. 1997. Importance of marinas and off-channel water bodies as refuges for young fishes in a regulated lowland river. Regulated Rivers: Research and Management 13: 303-307.

Courtois, L. A. 1981. Lightweight, adjustable, and portable surgical table for fisheries work in the field. The Progressive Fish-Culturist 43:55-56.

Fullerton, A. H., J. E. Garvey, R. A. Wright, and R. A. Stein. 2000. Overwinter growth and survival of largemouth bass: interactions among size, food, origin, and winter severity. Transactions of the American Fisheries Society 129:1-12.

Freund, J. G. 2001. Seasonal movement and macro-habitat use of largemouth bass in an Ohio River navigation pool. Masters Thesis, West Virginia University.

Gent, R., J. Pitlo Jr., and T. Boland. 1995. Largemouth bass response to habitat and water quality rehabilitation in a backwater of the upper Mississippi River. North American Journal of Fisheries Management 15:784-793.

Hart, L. G. and R. C. Summerfelt. 1975. Surgical procedures for implanting ultrasonic transmitters into flathead catfish (Pylodictis olivaris). Transactions of the American Fisheries Society 104:56-59.

Hayes, D. B., W. W. Taylor, and H. L. Schramm, Jr. 1995. Predicting the biological impacts of competitive fishing. North American Journal of Fisheries Management 18:422-431. 
Henley, D. T. 1990. Statewide fisheries investigation project. Kentucky Department of Fish and Wildlife Resources, Annual Report F-40, Frankfort.

Hershfeld, D. C., D. J. Orth, and L. A. Nielsen. 1986. Fish production in the Kanawha River and its relation to barge traffic. Polish Archives of Hydrobiology 33:295303.

Junk, W. J., P. B. Bayley, and R. E. Sparks. 1989. The flood pulse concept in riverfloodplain systems. In D. P. Dodge (ed.), Proceedings of the International Large River Symposium, Canadian Special Publications of Fisheries and Aquatic Sciences, pp. 110-127.

Kieffer, J.D., M. R. Kubacki, F. J. S. Phelan, D. P. Philipp, and B. L. Tufts. 1995. Effects of catch-and-release angling on nesting male smallmouth bass. Transactions of the American Fisheries Society 124:70-76.

Klindt, R. M. and A. Schiavone, Jr. 1991. Post-release mortality and movements of tournament caught largemouth and smallmouth bass in the St. Lawrence River. New York State Department of Environmental Conservation.

Knights, B.C., B. L. Johnson, and M. B. Sandheinrich. 1995. Responses of bluegills and black crappie to dissolved oxygen, temperature, and current in backwater lakes of the upper Mississippi River during winter. North American Journal of Fisheries Management 15:390-399.

Kwak, T. J. 1988. Lateral movement and use of floodplain habitat by fishes of the Kankakee River, Illinois. The American Midland Naturalist 120:241-249.

Lee, D. S. 1980. Micropterus salmoides (Lacepede), largemouth bass. Page 608 in Lee, D. S., C. R. Gilbert, C. H. Hocutt, R. E. Jenkins, D. E. McAllister, and J. R. Stauffer Jr. Atlas of North American Freshwater Fishes. North Carolina Biological Survey.

Lehtinen, R. M., N. D. Mundahl, and J. C. Madejczyk. 1997. Autumn use of woody snags by fishes in backwater and channel border habitats of a large river. Environmental Biology of Fishes 49:7-19.

Madejczyk, J. C., N. D. Mundahl, and R. M. Lehtinen. 1998. Fish assemblages of natural and artificial habitats within the channel border of the Upper Mississippi River. The American Midland Naturalist 139:296-310.

Mesing, C. and A. M. Wicker, 1986. Home range, spawing migrations, and homing of radio-tagged Florida largemouth bass in two Central Florida lakes. Transactions of the American Fisheries Society 115: 286-295.

Nack, S. B., D. Bunnell, D. M. Green, and J. L. Forney. 1993. Spawning and nursery habitats of largemouth bass in the tidal Hudson River. Transactions of the American Fisheries Society 122:208-219. 
Nielsen, L. A., R. J. Sheehan, and D. J. Orth. 1986. Impacts of navigation on riverine fish production in the United States. Polish Archives of Hydrobiology 33:277-294.

ORSANCO. 1994. Ohio River Water Quality Fact Book, Cincinnati, OH.

Philipp, D. P., C. A. Toline, M. F. Kubacki, D. B. F. Philipp, and F. J. S. Phelan. 1997. The impact of catch-and-release angling on the reproductive success of smallmouth bass and largemouth bass. North American Journal of Fisheries Management 17:557-567.

Otis, K. J. and J. J. Weber. 1982. Movement of carp in the Lake Winnebago system determined by radio telemetry. Wisconsin Department of Natural Resouces Technical Bulletin 134.

Pitlo, J., Jr. 1992. An evaluation of largemouth bass populations in the upper Mississippi River. Iowa Department of Natural Resources, Federal Aid in Sport Fish Restoration, Project F-109-R, Final Report, Des Moines.

Poff, N. L. and J. D. Allan. 1995. Functional stream fish assemblages in relation to hydrological variability. Ecology 76:606-627.

Poff, N.L., J.D. Allan, M.B. Bain, J.R. Karr, K.L. Prestegaard, B.D. Richter, R.E. Sparks, and J.C. Stromberg. 1997. The natural flow regime: a paradigm for river conservation and restoration. BioScience 47:769-784.

Raibley, P. T., K. S. Irons, T. M. O'Hara, K. D. Blodgett, and R. E. Sparks. 1997a. Winter habitats used by largemouth bass in the Illinois River, a large riverfloodplain ecosystem. North American Journal of Fisheries Management 17:401412.

Raibley, P. T., T. M. O'Hara, K. S. Irons, K. D. Blodgett, and R. E. Sparks. 1997b. Largemouth bass size distributions under varying annual hydrological regimes in the Illinois River. Transactions of the American Fisheries Society 126:850-856.

Richardson-Heft, C. A., A. A. Heft, D. Fewlass, and S. B. Brandt. 2000. Movement of largemouth bass in northern Chesapeake Bay: relevance to sportfishing tournaments. North American Journal of Fisheries Management 20:493-501.

Ridgway, M. S., B. J. Shuter, and E. E. Post. 1991. The relative influence of body size and territorial behaviour on nesting asynchrony in male smallmouth bass, Micropterus dolomieui (Pisces: Centrarchidae). Journal of Animal Ecology 60:665-681.

Samuel, M.D. and K. P. Kenow. 1992. Evaluating habitat selection with radio-telemetry triangulation error. Journal of Wildlife Management 56:725-734.

Schramm, H. L., Jr., and 9 co-authors. 1991. Sociological, economic, and biological aspects of competitive fishing. Fisheries 16(3):13-21. 
Sheaffer, W. A. and J. G. Nickum. 1986. Backwater areas as nursery habitats for fishes in pool 13 of the upper Mississippi River. Hydrobiologia 136:131-140.

Sheehan, R. J., W. M. Lewis, L. R. Bodensteiner, M. Schmidt, E. Sandberg, and G. Conover. 1994. Winter habitat requirements and overwintering of riverine fishes. $160 \mathrm{pp}$.

Sheehan, R. J. and J. L. Rasmussen. 1999. Large Rivers. In: Kohler, C.C. and W. A. Hubert (eds.), Inland Fisheries Management in North America, American Fisheries Society, Bethesda, MD.

Sheldon, A. L. 1968. Species diversity and longitudinal succession in stream fishes. Ecology 49:193-198.

Stasko, A.B. and D. G. Pincock. 1977. Review of underwater biotelemetry, with emphasis on ultrasonic techniques. Journal of the Fisheries Research Board of Canada 34:1261-1285.

Vallaza, J. M. 1995. Seasonal movement and habitat use of hybrid striped bass in the Ohio River. Masters Thesis. The Ohio State University.

Vannote, R. L., G. W. Winshall, K. W. Cummins, J. R. Sedell, and C. E. Cushing. 1980. The river continuum concept. Canadian Journal of Fisheries and Aquatic Sciences 37:130-137.

Winter, J., 1996. Advances in underwater biotelemetry. In: Murphy, B.R. and D. W. Willis (eds.), Fisheries Techniques, American Fisheries Society, Bethesda, Maryland, pp. 555-590. 
Table 1. Radio frequency, date of transmitter implantation, relative transmitter size, largemouth bass total length, and weight. Small transmitters are $8 \mathrm{~g}$, medium transmitters are $12 \mathrm{~g}$, and large transmitters are $17 \mathrm{~g}$. Transmitter size was less than $2 \%$ of the fish's body weight.

\begin{tabular}{|c|c|c|c|c|}
\hline $\begin{array}{l}\text { Transmitter } \\
\text { Frequency }\end{array}$ & $\begin{array}{c}\text { Date of } \\
\text { Implantation }\end{array}$ & $\begin{array}{c}\text { Transmitter } \\
\text { Size }\end{array}$ & $\begin{array}{c}\text { Length } \\
(\mathrm{mm})\end{array}$ & Weight (g) \\
\hline 48.011 & 09/18/99 & Small & 403 & . \\
\hline 48.022 & 09/18/99 & Small & 373 & 724 \\
\hline 48.032 & 09/18/99 & Small & 351 & 639 \\
\hline 48.042 & 09/18/99 & Small & . & 838 \\
\hline 48.052 & 09/18/99 & Small & 355 & 696 \\
\hline 48.062 & 09/18/99 & Small & 340 & 483 \\
\hline 48.071 & 09/18/99 & Small & 378 & 781 \\
\hline 48.082 & 09/18/99 & Small & 397 & 1023 \\
\hline 48.241 & 05/09/00 & Small & 410 & 998 \\
\hline 48.272 & 05/09/00 & Small & 416 & 1134 \\
\hline 48.675 & $08 / 14 / 99$ & Small & 360 & 455 \\
\hline 48.695 & 08/14/99 & Small & 350 & 564 \\
\hline 48.715 & $08 / 14 / 99$ & Small & 365 & 736 \\
\hline 48.735 & 08/14/99 & Small & 390 & 750 \\
\hline 49.014 & 03/30/99 & Large & . & . \\
\hline 49.034 & 09/19/98 & Large & 429 & 1227 \\
\hline
\end{tabular}




\begin{tabular}{|c|c|c|c|}
\hline 49.054 & 08/14/99 & Large & 407 \\
\hline 49.075 & $04 / 23 / 99$ & Large & . \\
\hline 49.095 & $04 / 25 / 99$ & Large & 415 \\
\hline 49.111 & $08 / 15 / 98$ & Large & 454 \\
\hline 49.134 & $04 / 23 / 99$ & Large & 432 \\
\hline 49.140 & $07 / 02 / 98$ & Large & 380 \\
\hline 49.154 & 08/14/99 & Large & 379 \\
\hline 49.170 & $08 / 15 / 98$ & Large & 413 \\
\hline 49.194 & $07 / 15 / 99$ & Large & 390 \\
\hline 49.201 & 08/15/98 & Large & 417 \\
\hline 49.230 & 07/03/98 & Large & 476 \\
\hline 49.337 & $04 / 26 / 99$ & Medium & 350 \\
\hline 49.354 & $04 / 23 / 99$ & Medium & 361 \\
\hline 49.367 & $04 / 23 / 99$ & Medium & 315 \\
\hline 49.384 & $12 / 06 / 98$ & Medium & 356 \\
\hline 49.398 & 08/14/99 & Medium & 375 \\
\hline 49.413 & $05 / 14 / 99$ & Small & 336 \\
\hline 49.428 & $10 / 25 / 98$ & Small & 327 \\
\hline 49.444 & $12 / 06 / 98$ & Small & 308 \\
\hline 49.457 & $10 / 25 / 98$ & Small & 307 \\
\hline 49.474 & 04/23/99 & Small & 305 \\
\hline 49.494 & 08/14/99 & Large & 420 \\
\hline
\end{tabular}


49.514

05/15/99

Large

1273

$-2$ 
Table 2. Summary of transmitter frequency, date of implantation, capture method, capture habitat, and capture location. Fish obtained by angling were caught at black bass tournaments and the location of capture is often unknown. (Table 3 describes the release location of tournament caught fish.)

\begin{tabular}{|c|c|c|c|c|}
\hline $\begin{array}{l}\text { Transmitter } \\
\text { Frequency }\end{array}$ & Date Tagged & $\begin{array}{l}\text { Capture } \\
\text { Method }\end{array}$ & $\begin{array}{l}\text { Capture } \\
\text { Habitat }\end{array}$ & Capture Location \\
\hline 48.011 & 09/18/99 & Angling & Unknown & $\begin{array}{l}\text { Parkersburg } \\
\text { Tournament }\end{array}$ \\
\hline 48.022 & 09/18/99 & Angling & Unknown & $\begin{array}{l}\text { Parkersburg } \\
\text { Tournament }\end{array}$ \\
\hline 48.032 & 09/18/99 & Angling & Unknown & $\begin{array}{l}\text { Parkersburg } \\
\text { Tournament }\end{array}$ \\
\hline 48.042 & 09/18/99 & Angling & Unknown & $\begin{array}{l}\text { Parkersburg } \\
\text { Tournament }\end{array}$ \\
\hline 48.052 & 09/18/99 & Angling & Unknown & $\begin{array}{l}\text { Parkersburg } \\
\text { Tournament }\end{array}$ \\
\hline 48.062 & 09/18/99 & Angling & Unknown & $\begin{array}{l}\text { Parkersburg } \\
\text { Tournament }\end{array}$ \\
\hline 48.071 & 09/18/99 & Angling & Unknown & $\begin{array}{l}\text { Parkersburg } \\
\text { Tournament }\end{array}$ \\
\hline 48.082 & 09/18/99 & Angling & Unknown & $\begin{array}{l}\text { Parkersburg } \\
\text { Tournament }\end{array}$ \\
\hline 48.241 & 05/09/00 & Electrofishing & Embayment & Lee Creek \\
\hline 48.272 & 05/09/00 & Electrofishing & Embayment & Lee Creek \\
\hline 48.675 & 08/14/99 & Angling & Unknown & Belpre Tournament \\
\hline
\end{tabular}




\begin{tabular}{|c|c|c|c|c|}
\hline 48.695 & $08 / 14 / 99$ & Angling & Unknown & Belpre Tournament \\
\hline 48.715 & 08/14/99 & Angling & Unknown & Belpre Tournament \\
\hline 48.735 & 08/14/99 & Angling & Unknown & Belpre Tournament \\
\hline 49.014 & 03/30/99 & Electrofishing & Embayment & Lee Creek \\
\hline 49.034 & 09/19/98 & Angling & Main River & $\begin{array}{l}\text { Parkersburg } \\
\text { Tournament }\end{array}$ \\
\hline 49.054 & 08/14/99 & Angling & Unknown & Belpre Tournament \\
\hline 49.075 & $04 / 23 / 99$ & Electrofishing & Embayment & Lee Creek \\
\hline 49.095 & $04 / 25 / 99$ & Electrofishing & Embayment & Sugar Camp Run \\
\hline 49.111 & $08 / 15 / 98$ & Angling & Main River & Belpre Tournament \\
\hline 49.134 & $04 / 23 / 99$ & Electrofishing & Embayment & Lee Creek \\
\hline 49.140 & $07 / 02 / 98$ & Electrofishing & Embayment & Lee Creek \\
\hline 49.154 & 08/14/99 & Angling & Unknown & Belpre Tournament \\
\hline 49.170 & 08/15/98 & Angling & Main River & Belpre Tournament \\
\hline 49.194 & 07/15/99 & Electrofishing & Main River & Williamstown, WV \\
\hline
\end{tabular}




\begin{tabular}{|c|c|c|c|c|}
\hline 49.201 & $08 / 15 / 98$ & Angling & Embayment & Belpre Tournament \\
\hline 49.230 & 07/03/98 & Electrofishing & Embayment & Lee Creek \\
\hline 49.337 & $04 / 26 / 99$ & Electrofishing & Embayment & Rock Run \\
\hline 49.354 & $04 / 23 / 99$ & Electrofishing & Embayment & Sugar Camp Run \\
\hline 49.367 & $04 / 23 / 99$ & Electrofishing & Embayment & Lee Creek \\
\hline 49.384 & $12 / 06 / 98$ & Electrofishing & Embayment & Swan Run \\
\hline 49.398 & $08 / 14 / 99$ & Angling & Unknown & Belpre Tournament \\
\hline 49.413 & $05 / 14 / 99$ & Electrofishing & Embayment & Lee Creek \\
\hline 49.428 & $10 / 25 / 98$ & Electrofishing & Embayment & Swan Run \\
\hline 49.444 & $12 / 06 / 98$ & Electrofishing & Embayment & Swan Run \\
\hline 49.457 & $10 / 25 / 98$ & Electrofishing & Embayment & Swan Run \\
\hline 49.474 & $04 / 23 / 99$ & Electrofishing & Embayment & Lee Creek \\
\hline 49.494 & 08/14/99 & Angling & Unknown & Belpre Tournament \\
\hline 49.514 & $05 / 15 / 99$ & Angling & Unknown & Belpre Tournament \\
\hline
\end{tabular}


Table 3. Summary of release locations for tournament caught largemouth bass implanted with radio transmitters.

\begin{tabular}{cllc}
\hline \multicolumn{1}{c}{ Date } & \multicolumn{1}{c}{ Location } & \multicolumn{1}{c}{ Release Site } & Release Habitat \\
\hline $08 / 15 / 98$ & Belpre, OH & Mustapha Island main channel & Main River \\
$09 / 19 / 98$ & Parkersburg, WV & Little Kanawha River & Tributary \\
$05 / 15 / 99$ & Belpre, OH & Belpre Boat Ramp & Main River \\
$08 / 14 / 99$ & Belpre, OH & Blennerhasset Island main channel & Main River \\
$09 / 18 / 99$ & Parkersburg, WV & Blennerhasset Island back channel & Main River \\
\hline
\end{tabular}


Table 4. Summary of tag frequencies of individual largemouth bass, the number of times they were detected while conducting radio telemetry searches, the date the fish was first located and last located, and the total number of days the transmitter was active between the first and last times the fish was located via radio telemetry.

\begin{tabular}{|c|c|c|c|c|}
\hline Frequency & $\begin{array}{c}\text { \# of times } \\
\text { located }\end{array}$ & $\begin{array}{l}\text { Date first } \\
\text { located }\end{array}$ & $\begin{array}{l}\text { Date last } \\
\text { located }\end{array}$ & $\begin{array}{c}\text { \# of active } \\
\text { days }\end{array}$ \\
\hline 48.011 & 16 & $10 / 29 / 99$ & $05 / 20 / 00$ & 204 \\
\hline 48.022 & 1 & $04 / 30 / 00$ & $04 / 30 / 00$ & 1 \\
\hline 48.032 & 13 & 10/01/99 & $05 / 20 / 00$ & 232 \\
\hline 48.052 & 19 & $10 / 29 / 99$ & $05 / 20 / 00$ & 204 \\
\hline 48.062 & 19 & $10 / 29 / 99$ & 06/01/00 & 216 \\
\hline 48.071 & 9 & $02 / 17 / 00$ & $06 / 05 / 00$ & 109 \\
\hline 48.082 & 18 & 10/01/99 & $06 / 05 / 00$ & 248 \\
\hline 48.241 & 4 & $05 / 20 / 00$ & 06/09/00 & 20 \\
\hline 48.675 & 17 & 08/30/99 & $04 / 07 / 00$ & 221 \\
\hline 48.695 & 14 & 09/13/99 & $06 / 01 / 00$ & 262 \\
\hline 48.715 & 7 & 09/03/99 & $02 / 05 / 00$ & 155 \\
\hline 48.735 & 17 & 08/30/99 & $03 / 30 / 00$ & 213 \\
\hline 49.011 & 1 & $05 / 17 / 00$ & $05 / 17 / 00$ & 1 \\
\hline 49.014 & 36 & 04/19/99 & 06/09/00 & 417 \\
\hline 49.034 & 1 & $10 / 10 / 98$ & $10 / 10 / 98$ & 1 \\
\hline 49.095 & 13 & 05/29/99 & 06/04/00 & 372 \\
\hline
\end{tabular}




\begin{tabular}{|c|c|c|c|c|}
\hline 49.111 & 1 & 05/29/99 & 05/29/99 & 1 \\
\hline 49.134 & 9 & $05 / 04 / 99$ & $12 / 04 / 99$ & 214 \\
\hline 19.140 & 4 & $02 / 22 / 99$ & 03/29/99 & 35 \\
\hline 49.154 & 20 & 08/30/99 & 05/17/00 & 261 \\
\hline 49.194 & 17 & $12 / 04 / 99$ & 06/08/00 & 187 \\
\hline 49.230 & 36 & 08/30/98 & 05/13/99 & 256 \\
\hline 49.337 & 4 & 05/13/99 & 06/19/99 & 37 \\
\hline 49.367 & 9 & 05/04/99 & 08/05/99 & 93 \\
\hline 49.384 & 5 & 03/12/99 & 05/04/99 & 53 \\
\hline 48.428 & 8 & $11 / 22 / 98$ & 02/22/99 & 92 \\
\hline 48.444 & 11 & $01 / 17 / 99$ & $04 / 25 / 99$ & 98 \\
\hline 49.457 & 20 & $11 / 07 / 98$ & 05/13/99 & 187 \\
\hline 49.494 & 1 & 09/03/99 & 09/03/99 & 1 \\
\hline 49.514 & 8 & 06/18/99 & 03/26/00 & 282 \\
\hline
\end{tabular}


Table 5. Chi-square analysis of overall and seasonal habitat use by largemouth bass in the Belleville Pool of the Ohio River. Habitat selection occurred during all seasons.

Total values in bold were compared to $\mathrm{a} \dot{\circ}^{2}$ critical value of $5.991(a ́=0.05, \mathrm{df}=2)$.

\begin{tabular}{|c|c|c|c|c|}
\hline & Embayment & Main Channel & Tributary & Total \\
\hline Spring (observed) & 53 & 27 & 31 & 111 \\
\hline Spring (\%) & 47.75 & 24.32 & 27.93 & 100.00 \\
\hline Spring (expected) & 5.56 & 94.17 & 11.27 & 111 \\
\hline Spring (Chi-Square) & 404.68 & 47.91 & 34.56 & 487.15 \\
\hline Relative Contribution (\%) & 83.07 & 9.84 & 7.10 & \\
\hline Summer (observed) & 22 & 20 & 0 & 42 \\
\hline Summer $(\%)$ & 52.38 & 47.62 & 0.00 & 100.00 \\
\hline Summer (expected) & 2.10 & 35.63 & 4.26 & 42 \\
\hline Summer (Chi-Square) & 188.12 & 6.86 & 4.26 & 199.24 \\
\hline Relative Contribution (\%) & 94.42 & 3.44 & 2.14 & \\
\hline Fall (observed) & 27 & 22 & 9 & 58 \\
\hline Fall $(\%)$ & 46.55 & 37.93 & 15.52 & 100.00 \\
\hline Fall (expected) & 2.91 & 49.21 & 5.89 & 58 \\
\hline Fall (Chi-Square) & 199.78 & 15.04 & 1.65 & 216.47 \\
\hline Relative Contribution ( $\%$ ) & 92.29 & 6.95 & 0.76 & \\
\hline Winter (observed) & 65 & 58 & 23 & 146 \\
\hline Winter (\%) & 44.52 & 39.73 & 15.75 & 100.00 \\
\hline Winter (expected) & 7.31 & 123.87 & 14.82 & 146 \\
\hline Winter (Chi-Square) & 454.93 & 35.02 & 4.52 & 494.47 \\
\hline Relative Contribution (\%) & 92.00 & 7.08 & 0.91 & \\
\hline Overall (observed) & 167 & 127 & 63 & 357 \\
\hline Overall (\%) & 46.78 & 35.57 & 17.65 & 100.00 \\
\hline Overall (expected) & 17.89 & 302.88 & 36.24 & 357 \\
\hline Overall (Chi-Square) & 1243.18 & 102.13 & 19.77 & 1365.08 \\
\hline Relative Contribution ( $\%$ ) & 91.07 & 7.48 & 1.45 & \\
\hline$\%$ of Available Habitat & 5.01 & 84.84 & 10.15 & \\
\hline
\end{tabular}


Table 6. Effect of capture method on habitat use by largemouth bass analyzed by a ChiSquare goodness of fit test. The total $\div^{2}$ test statistic for angling and electrofishing are each compared to a critical value of $5.991(a ́=0.05, \mathrm{df}=2)$.

\begin{tabular}{rrr}
\hline & Angling & Electrofishing \\
\hline Embayment (observed) & 18 & 149 \\
Embayment (\%) & 9.94 & 84.66 \\
Embayment (expected) & 9.0681 & 8.8176 \\
Embayment (Chi-Square) & 8.798 & 2228.623 \\
Relative Contribution (\%) & $\mathbf{6 . 4 7}$ & $\mathbf{9 4 . 9 7}$ \\
Main River (observed) & & \\
Main River (\%) & 100 & 27 \\
Main River (expected) & 153.5604 & 149.3184 \\
Main River (Chi-Square) & 18.681 & 100.201 \\
Relative Contribution (\%) & $\mathbf{1 3 . 7 5}$ & $\mathbf{4 . 2 7}$ \\
Tributary (observed) & & 0 \\
Tributary (\%) & 63 & 0 \\
Tributary (expected) & 18.3715 & 17.8640 \\
Tributary (Chi-Square) & 108.413 & $\mathbf{7 9}$ \\
Relative Contribution (\%) & $\mathbf{7 9 . 7 8}$ & $\mathbf{0 . 7 6}$ \\
Totals & 181 & $\mathbf{2 3 4 6 . 6 8 7}$ \\
\hline Total (Chi-Square) & $\mathbf{1 3 5 . 8 9 2}$ & \\
\hline
\end{tabular}


Figure 1. Position of United States Army Corps of Engineers navigation dams in relation to the state of West Virginia.

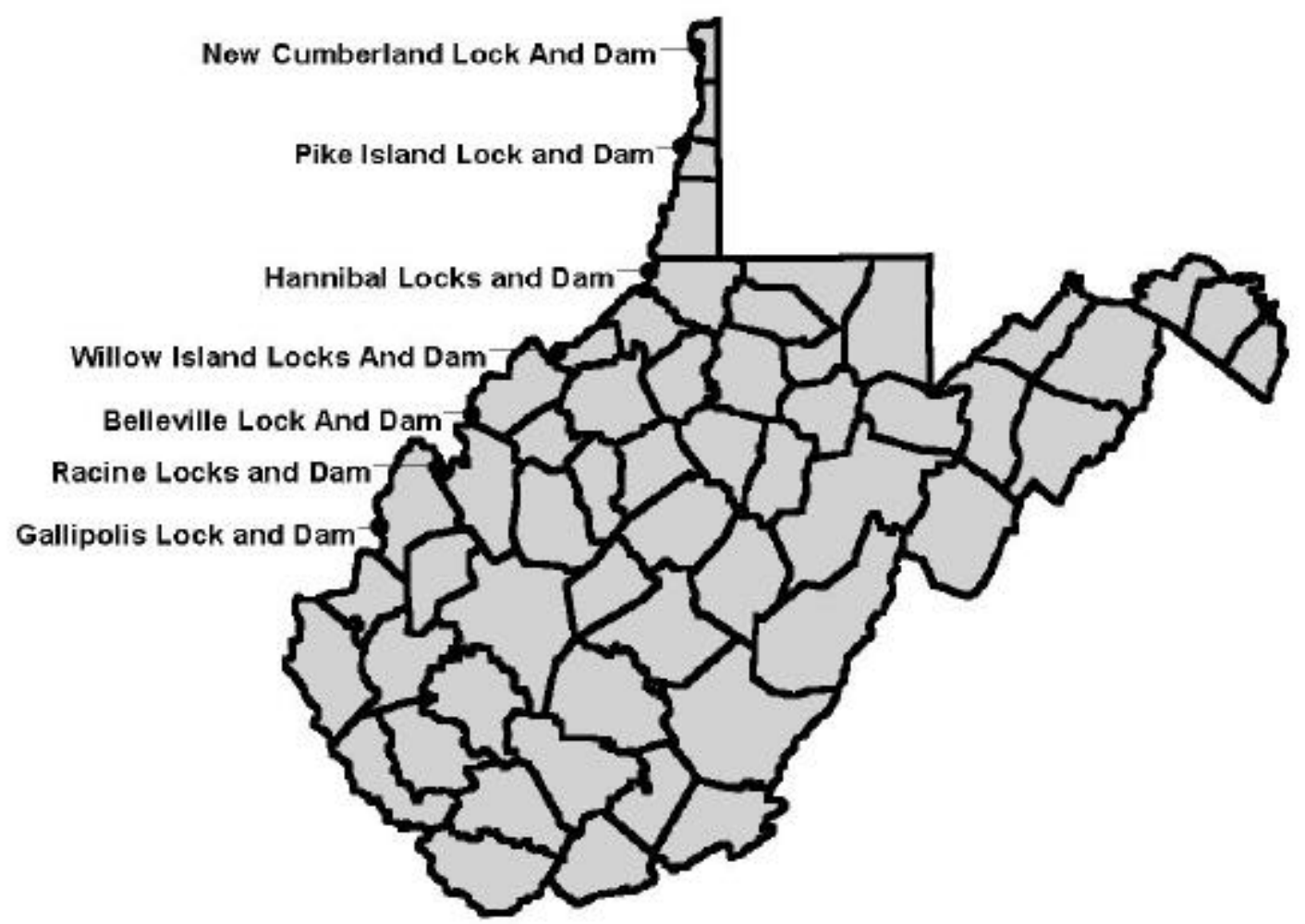


Figure 2. The Belleville Pool of the Ohio River and its relation to West Virginia including major cities and Army Corps of Engineers navigation dams.

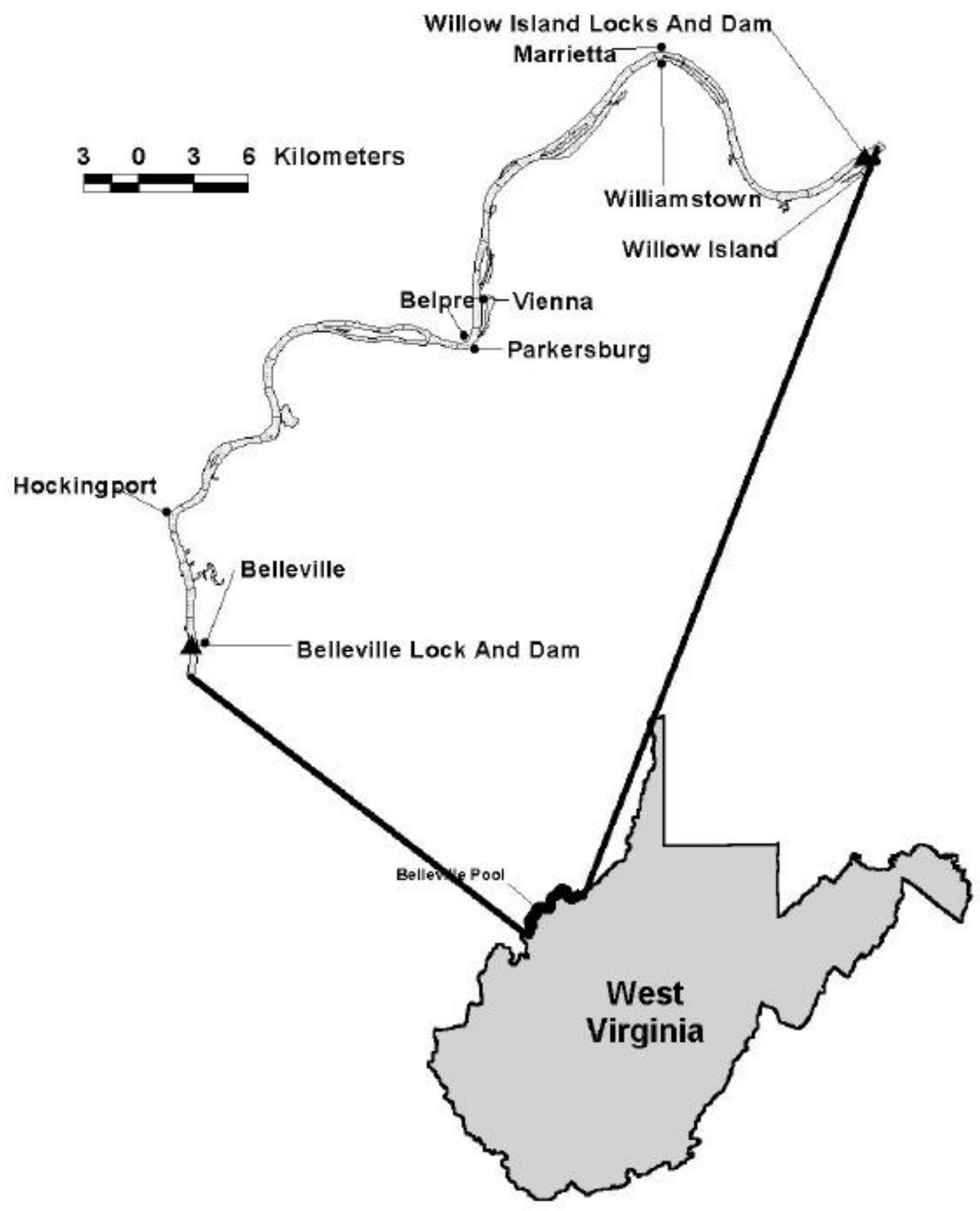


Figure 3. Macro-habitat units (Main Channel, Embayment, and Tributary) in the Belleville Pool of the Ohio River. Main Channel habitats are further dissected into main channel, back channel, and main-channel border. See Methods for further description of macro-scale habitat units.

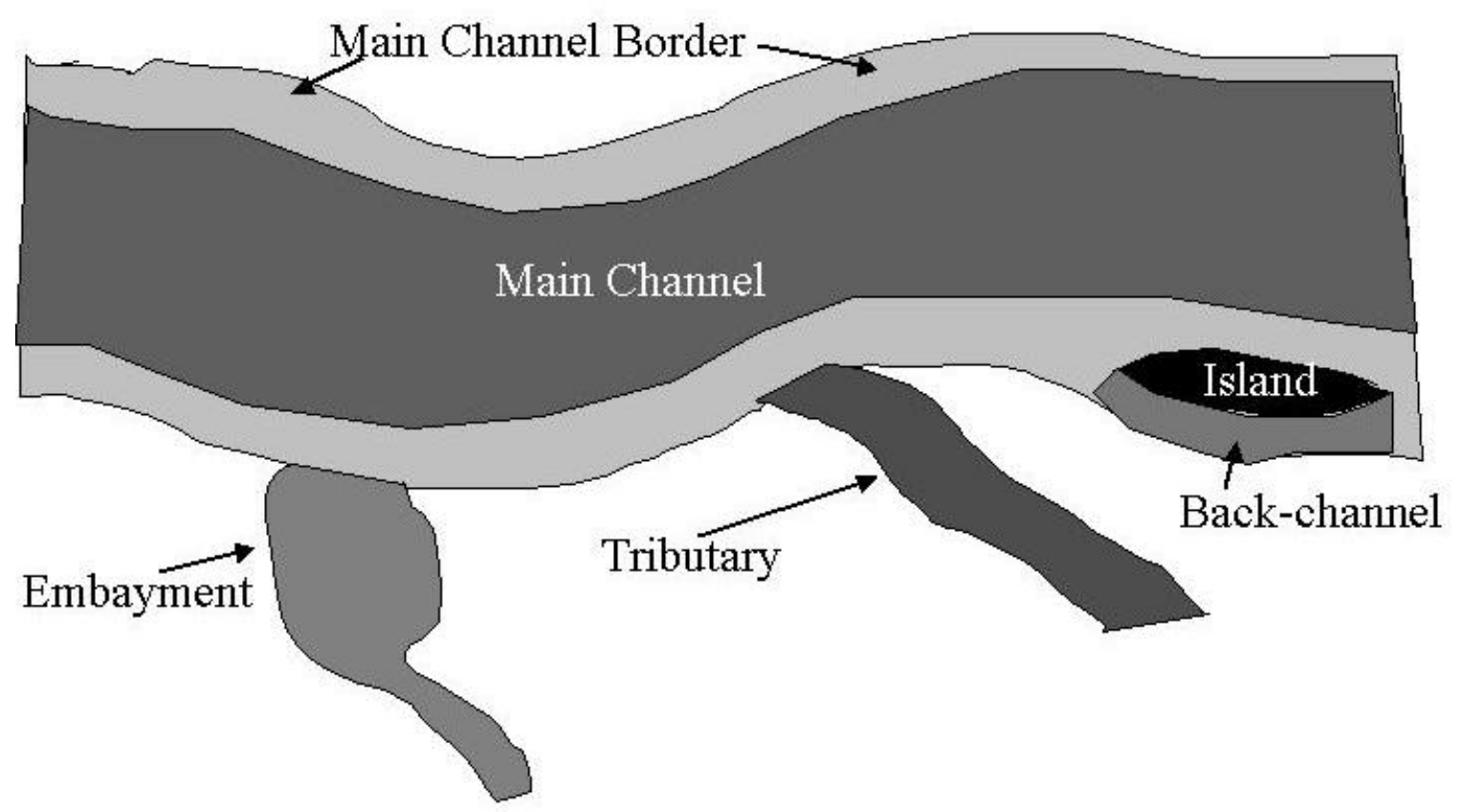


Figure 4. Seasonal habitat availability and use by largemouth bass in the Belleville Pool of the Ohio River as determined by radio telemetry. Seasons were: spring (April through June), summer (July through September), fall (October and November), and winter (December through March).

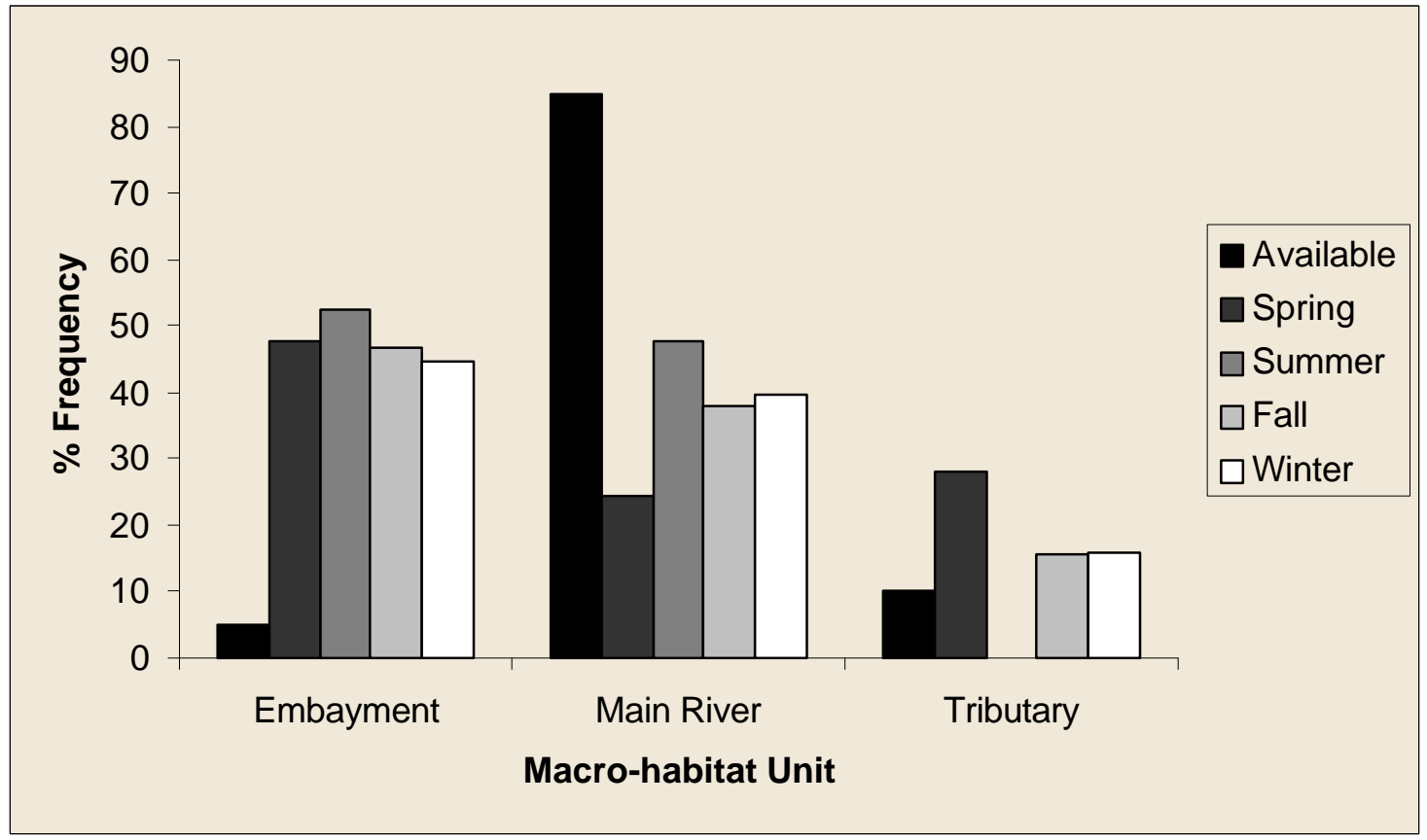


Figure 5. Winter and spring habitat use of macro-habitat units in the Belleville Pool of the Ohio River. Expected values are related to the amount of available habitat of each macro-habitat unit.

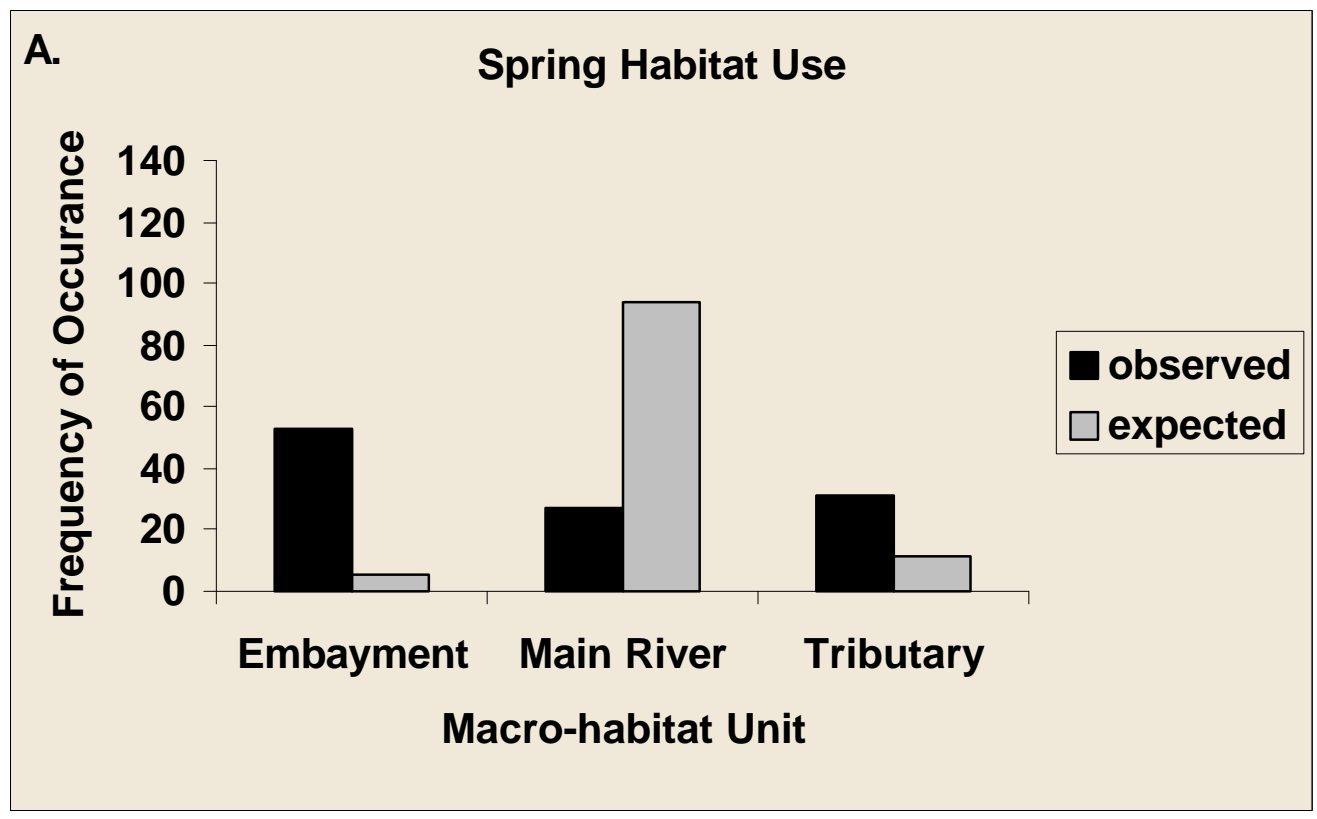

B.

\section{Winter Habitat Use}

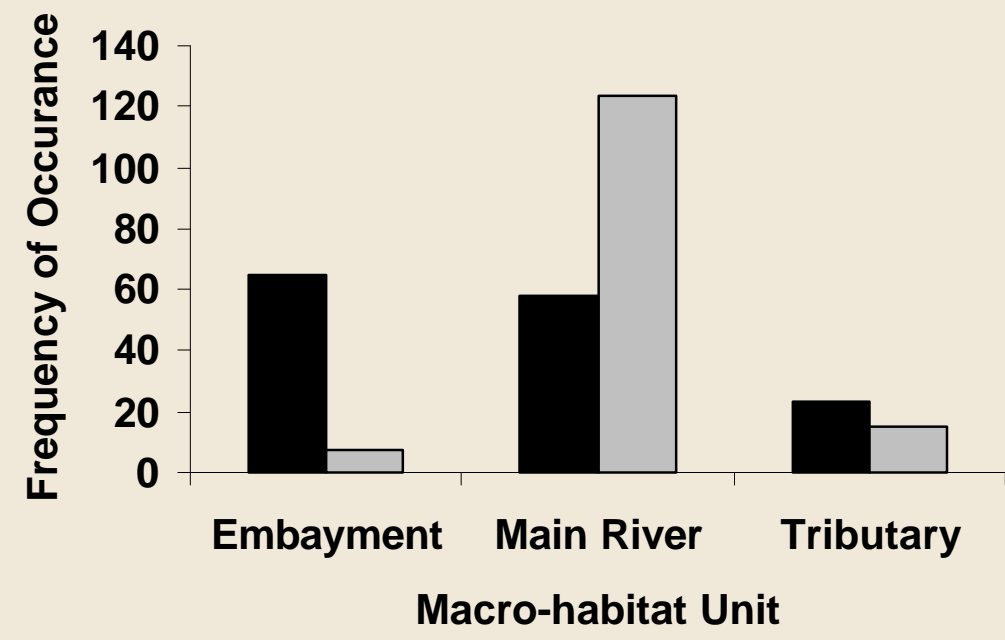


Figure 6. Movement of a largemouth bass implanted with a radio transmitter with a frequency of 49.230 MHz. Site A had 7 summer and 1 winter records; B had 2 summer, 9 fall, and 4 spring records; C had 3 fall and 3 winter records; while D had a single winter record.

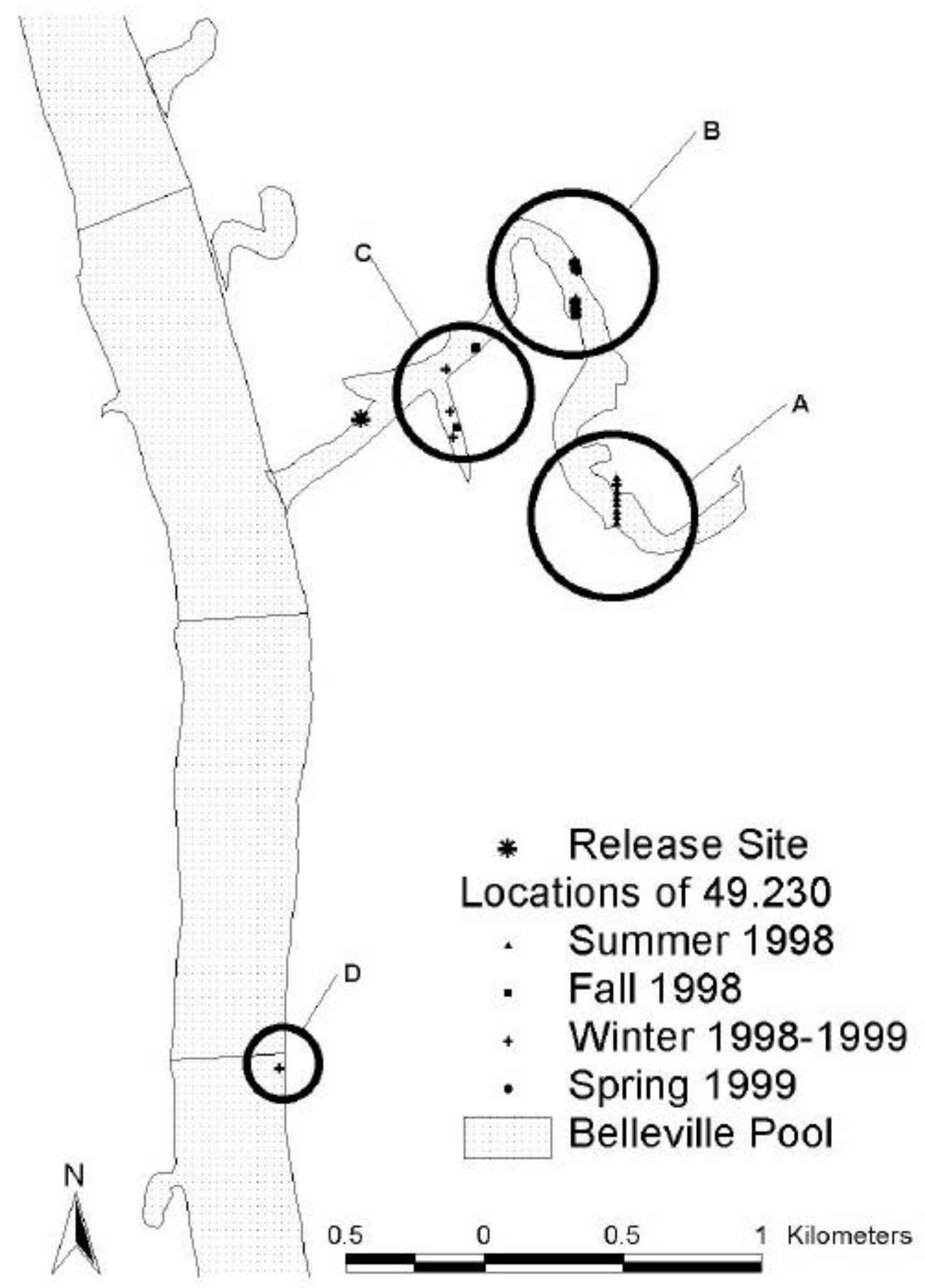


Figure 7. Movement of a largemouth bass implanted with a radio transmitter with a frequency of $48.082 \mathrm{MHz}$. Site A had a single fall record; B had 3 fall and 5 winter records; C had 2 winter records; and D had 3 spring records.

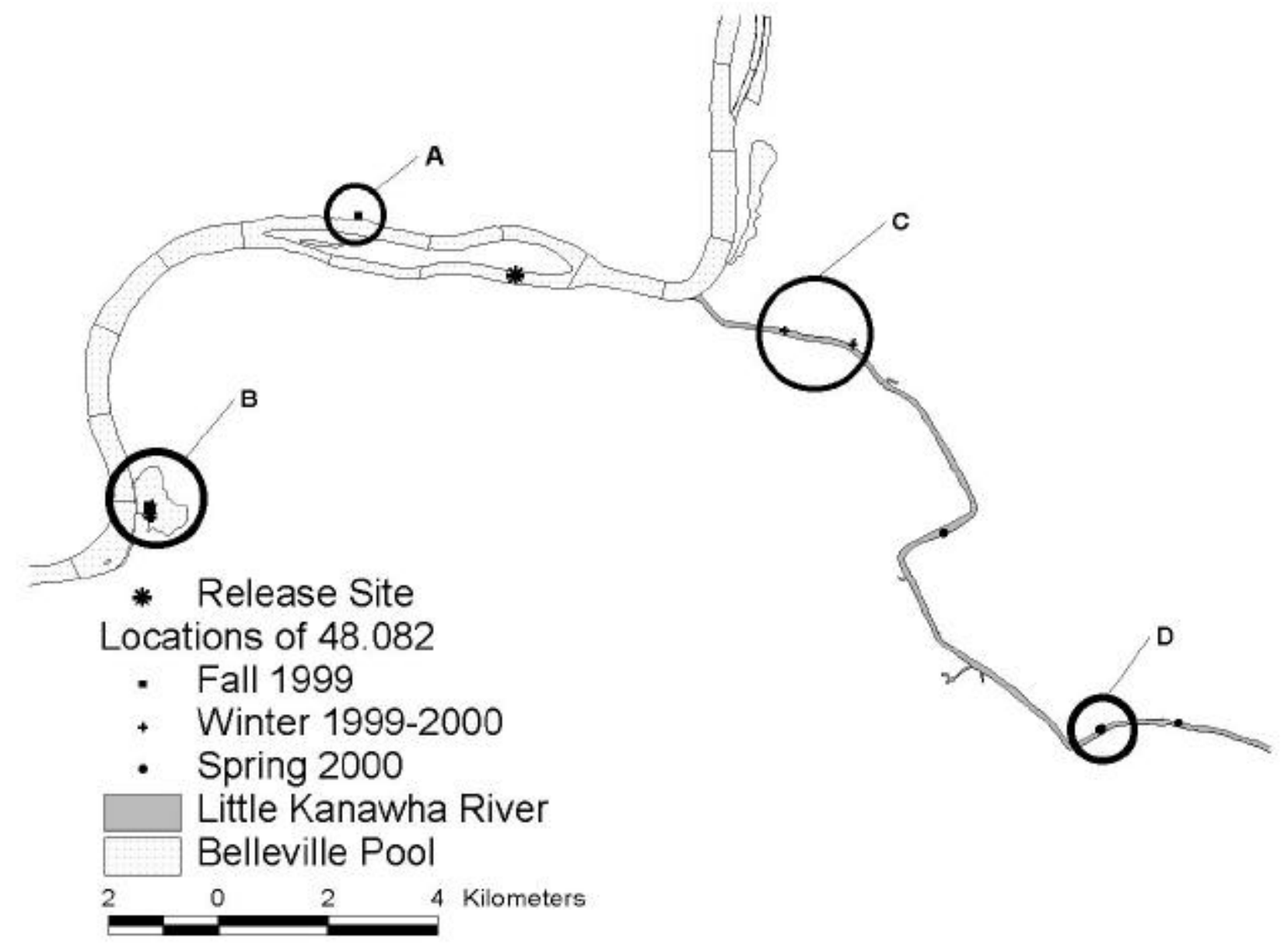




\title{
Curriculum Vitae
}

\author{
Jason G. Freund \\ West Virginia University \\ Division of Forestry \\ P.O. Box 6125 \\ Morgantown, WV 26506-6125 \\ (304) 293-2941 extension 2427 \\ Fax: (304) 293-2441 \\ jfreund@wvu.edu
}

Education:

Present West Virginia University, Morgantown, West Virginia

M.S. in Fisheries

Thesis: "Over-wintering and Spawning Habitat Selection of Largemouth Bass in the Belleville Pool of the Ohio River" Major Professor: Kyle J. Hartman

May 1995

University of Wisconsin - Platteville, Platteville, Wisconsin B.S. in Biology, Zoology and Field Biology Emphases Graduated Summa cum Laude

\section{Work Experience:}

May 1995 -

August 1997

May 1994-

August 1994
Research Technician, University of Wisconsin - Madison Department of Agronomy, Forage Research and Extension Conducted field research on effects of cattle grazing on grassland songbirds and effects of cattle grazing on cold-water stream habitat, fishes, and macroinvertebrates under the direction of Dr. Daniel Undersander. In addition, I designed the laboratory's web site.

Assistant Crew Leader, Wisconsin Youth Conservation Corps Completed the restoration of flood-damaged sites at the Pendarvis House State Historic Site and completed a trout stream restoration project at Yellowstone Lake State Wildlife Area. 


\section{Teaching Experience:}

Fall 1997

Spring 1998
Teaching Assistant, Introduction to Biology II Laboratory

West Virginia University, Department of Biology

Taught biology laboratory for non-majors

Graduate Teaching Assistant, Ecology and Evolutionary Biology

West Virginia University, Department of Biology

Taught biology laboratory to biology majors in which I acted as

the student's major professor as the students completed

independent research projects.

\section{Publications}

Freund, J. G. and K. J. Hartman. In Press. Influence of depth on detection distance of low-frequency radio transmitters in the Ohio River. North American Journal of Fisheries Management.

Petty, J. T., J. G. Freund, P. L. Lamothe, and P. Mazik. 2002. Quantifying the microhabitat characteristics of hydraulic channel units in the upper Shavers Fork Basin. Proceedings of the Annual Conference of Southeastern Fish and Wildlife Agencies. 55.

Freund, J. G. and K. J. Hartman. In Review. Seasonal habitat use by largemouth bass in an Ohio River navigation pool. North American Journal of Fisheries Management.

\section{Selected Presented Papers:}

"Quantifying the microhabitat characteristics of hydraulic channel units in the upper Shavers Fork Basin." Paper presented at the Southeastern Association of Fish and Wildlife Agencies Annual Meeting. Louisville, KY. October 2001.

"Over-wintering Habitat Selection of Largemouth Bass in the Belleville Pool of the Ohio River." Paper presented at the Tri-State American Fisheries Society Meeting. Ashland, KY. March 1999.

"Evaluation of a Pilot Largemouth Bass Stocking Project Utilizing Radio Telemetry." Paper presented at the Southern Division American Fisheries Society Mid-Year Meeting. Chattanooga, TN. February 1999. 


\section{Professional Societies:}

American Fisheries Society, National Chapter

American Fisheries Society, West Virginia Chapter

1998-1999 President, West Virginia University Student Chapter of the Wildlife Society and the American Fisheries Society

Ecological Society of America

Ecological Society of America, Aquatic Ecology Sub-Unit

Xi Sigma Pi

Phi Kappa Phi

\section{Outside Interests:}

- Fishing, particularly fly fishing and fly tying

- Hunting

- Reading

- Computers

- Hiking and backpacking

- Biking 